\title{
Unbiased Proteomics of Early Lewy Body Formation Model Implicates Active Microtubule Affinity-Regulating Kinases (MARKs) in Synucleinopathies
}

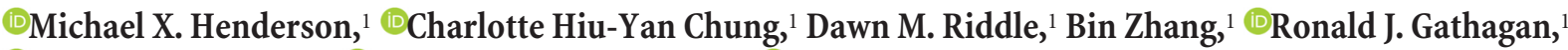 \\ (DSteven H. Seeholzer, ${ }^{2}{ }^{-}$John Q. Trojanowski, ${ }^{1}$ and ${ }^{\circ}$ Virginia M.Y. Lee ${ }^{1}$ \\ ${ }^{1}$ Department of Pathology and Laboratory Medicine, Institute on Aging and Center for Neurodegenerative Disease Research, University of Pennsylvania \\ School of Medicine, Philadelphia, Pennsylvania 19104, and ²Department of Pathology and Laboratory Medicine, Children's Hospital of Philadelphia, \\ Philadelphia, Pennsylvania 19104
}

Parkinson's disease (PD) patients progressively accumulate intracytoplasmic inclusions formed by misfolded $\alpha$-synuclein known as Lewy bodies (LBs). LBs also contain other proteins that may or may not be relevant in the disease process. To identify proteins involved early in LB formation, we performed proteomic analysis of insoluble proteins in a primary neuron culture model of $\alpha$-synuclein pathology. We identified proteins previously found in authentic LBs in PD as well as several novel proteins, including the microtubule affinityregulating kinase 1 (MARK1), one of the most enriched proteins in this model of LB formation. Activated MARK proteins (MARKs) accumulated in LB-like inclusions in this cell-based model as well as in a mouse model of LB disease and in LBs of postmortem synucleinopathy brains. Inhibition of MARKs dramatically exacerbated $\alpha$-synuclein pathology. These findings implicate MARKs early in synucleinopathy pathogenesis and as potential therapeutic drug targets.

Key words: $\alpha$-synuclein; dementia with Lewy bodies; microtubule affinity-regulating kinase; PAR-1; Parkinson's disease; synucleinopathy

Significance Statement

Neurodegenerative diseases are diagnosed definitively only in postmortem brains by the presence of key misfolded and aggregated disease proteins, but cellular processes leading to accumulation of these proteins have not been well elucidated. Parkinson's disease (PD) patients accumulate misfolded $\alpha$-synuclein in LBs, the diagnostic signatures of PD. Here, unbiased mass spectrometry was used to identify the microtubule affinity-regulating kinase family (MARKs) as activated and insoluble in a neuronal culture PD model. Aberrant activation of MARKs was also found in a PD mouse model and in postmortem PD brains. Further, inhibition of MARKs led to increased pathological $\alpha$-synuclein burden. We conclude that MARKs play a role in PD pathogenesis.

\section{Introduction}

Synucleinopathies, including Parkinson's disease without (PD) and with dementia (PDD), dementia with Lewy bodies (DLBs), and multiple system atrophy (MSA) are a group of neurodegenerative diseases characterized by the abnormal accumulations of

Received Aug. 26, 2016; revised March 22, 2017; accepted April 14, 2017.

Author contributions: M.X.H., C.H.-Y.C., S.H.S., J.Q.T., and V.M.Y.L. designed research; M.X.H., C.H.-Y.C., D.M.R., B.Z., and R.J.G. performed research; M.X.H., C.H.-Y.C., S.H.S., J.Q.T., and V.M.Y.L. analyzed data; M.X.H., J.Q.T., and V.M.Y.L. wrote the paper

This work was supported by National Institutes of Health Grants T32-AG000255, P30-AG10124, and P50NS053488 and the Keefer Family Foundation. We thank the patients and families who participated in this research and made this research possible; and Lynn Spruce and Chris McKennan for their assistance with mass spectrometry and data analysis.

The authors declare no competing financial interests.

Correspondence should be addressed to Dr. Virginia M.Y. Lee, 3600 Spruce Street, 3rd Floor Maloney, Philadelphia, PA 19104-4283. E-mail:vmylee@upenn.edu.

DOI:10.1523/JNEUROSCI.2705-16.2017

Copyright $\odot 2017$ the authors $\quad 0270-6474 / 17 / 375870-15 \$ 15.00 / 0$ $\alpha$-synuclein (Spillantini et al., 1997, 1998a, b; Goedert and Spillantini, 1998). While $\alpha$-synuclein is normally localized presynaptically (Iwai et al., 1995), $\alpha$-synuclein in diseased neurons misfolds and accumulates in detergent-insoluble neuronal aggregates known as Lewy bodies (LBs) (Spillantini et al., 1997). Pathogenic $\alpha$-synuclein gene (SNCA) duplication (Chartier-Harlin et al., 2004; Ibáñez et al., 2004), triplication (Singleton et al., 2003), and point mutations (A53T, A30P, E46K, G51D, H50Q, A53E) (Polymeropoulos et al., 1997; Krüger et al., 1998; Zarranz et al., 2004; Appel-Cresswell et al., 2013; Kiely et al., 2013; Proukakis et al., 2013; Pasanen et al., 2014) have been identified as the cause of familial PD in rare kindreds. However, the function of $\alpha$-synuclein remains elusive, as well as pathways leading to $\alpha$-synuclein misfolding events and protein degradation failure.

One clue to pathways that may be disrupted in LB pathogenesis has come from extensive analyses of protein components of LBs. For example, such studies have shown that $\alpha$-synuclein 
Table 1. Antibodies used for all studies ${ }^{a}$

\begin{tabular}{|c|c|c|c|c|c|c|c|}
\hline$\overline{\mathrm{RRID}}$ & Protein & Catalog\# & Company & Host & Western dilution & ICC dilution & Immunohistochemistry dilution \\
\hline$A B \_2273154$ & $14-3-3 \beta$ (pan) & SC-629 & Santa Cruz Biotechnology & Rabbit & $1: 1000$ & - & - \\
\hline AB_2289225 & $\beta$-actin & $60008-1-\lg$ & ProteinTech & Mouse & $1: 5000$ & - & - \\
\hline$A B \_634603$ & Catenin $\beta$ & SC-7199 & Santa Cruz Biotechnology & Rabbit & $1: 200$ & - & - \\
\hline$A B \_2081581$ & Collagen XII A1 & Sc-68862 & Santa Cruz Biotechnology & Rabbit & - & - & $1: 50$ \\
\hline$A B \_444361$ & DJ-1 & ab18257 & Abcam & Rabbit & $1: 2000$ & - & - \\
\hline$A B \_398423$ & DLP1 & 611112 & $B D$ & Mouse & $1: 2000$ & - & - \\
\hline NA & GAPDH & 2-RGM2 & Advanced Immunological & Mouse & $1: 3000$ & - & - \\
\hline$A B \_1078958$ & GBA & G4171 & Sigma & Rabbit & $1: 1000$ & - & - \\
\hline AB_11130507 & GRP78 & 210-137-C100 & Enzo Life Sciences & Rabbit & $1: 1000$ & - & - \\
\hline AB_10732804 & HECTD1 & 20605-1-AP & ProteinTech & Rabbit & $1: 500$ & - & - \\
\hline$A B \_2266164$ & HGK (MAP4K4) & SC-25738 & Santa Cruz Biotechnology & Rabbit & $1: 200$ & - & - \\
\hline$A B \_627759$ & Hsp70 & SC-32239 & Santa Cruz Biotechnology & Mouse & $1: 200$ & - & - \\
\hline$A B \_2548312$ & ITM2C & PA5-30838 & Thermo Fisher Scientific & Rabbit & $1: 1000$ & - & - \\
\hline AB_94284 & Kinesin $\mathrm{HC}$ & MAB1614 & Millipore & Mouse & $1: 500$ & - & - \\
\hline$A B \_2274121$ & $\mathrm{LC} 3$ & PM036 & $M B L$ & Rabbit & $1: 1000$ & - & - \\
\hline AB_10643781 & LRRK2 & $3514-1$ & Epitomics & Rabbit & $1: 2000$ & - & - \\
\hline NA & MAP2 & AP14 & CNDR & Mouse & - & $1: 5000$ & - \\
\hline NA & MAP2 & 17028 & CNDR & Rabbit & - & $1: 5000$ & - \\
\hline AB_10732726 & MARK1 & 21552-1-AP & ProteinTech & Rabbit & $1: 2000$ & - & $1: 50$ \\
\hline AB_2140752 & MARK2 & 15492-1-AP & ProteinTech & Rabbit & $1: 2000$ & - & $1: 50$ \\
\hline AB_2140607 & p-MARK & 4836 & Cell Signaling Technology & Rabbit & $1: 1000$ & $1: 500$ & $1: 500$ \\
\hline AB_10980994 & p-MARK (b) & PA5-17495 & Thermo Fisher Scientific & Rabbit & - & $1: 500$ & $1: 500$ \\
\hline AB_2298772 & NeuN & MAB377 & Millipore & Mouse & - & $1: 500$ & - \\
\hline$A B \_2532995$ & Neurofilament, light & $13-0400$ & Thermo Fisher Scientific & Mouse & $1: 500$ & - & - \\
\hline AB_2532996 & Neurofilament-medium & $13-0500$ & Zymed & Mouse & $1: 1000$ & - & - \\
\hline AB_2160225 & PAK1-3 & 2604 & Cell Signaling Technology & Rabbit & $1: 1000$ & - & - \\
\hline AB_2267950 & PAK2 & 2615 & Cell Signaling Technology & Rabbit & $1: 200$ & - & - \\
\hline AB_10675457 & PINK-1 & $73-060$ & NeuroMab & Mouse & $1: 500$ & - & - \\
\hline$A B \_437085$ & p62 & H00008878-M01 & Abnova & Mouse & $1: 1000$ & $1: 1000$ & $1: 1000$ \\
\hline NA & Parkin & 109.3 & CNDR & Mouse & $1: 1000$ & - & - \\
\hline$A B \_2165496$ & $\operatorname{PLC} \beta 1$ & sc -9050 & Santa Cruz Biotechnology & Rabbit & $1: 200$ & - & - \\
\hline$A B \_2300649$ & Rab5 & 3547 & Cell Signaling Technology & Rabbit & 1:1000 & - & - \\
\hline$A B \_1904103$ & Rab7 & 9367 & Cell Signaling Technology & Rabbit & $1: 1000$ & - & - \\
\hline$A B \_10624273$ & RAB33B & GTX116390 & GeneTex & Rabbit & $1: 500$ & - & - \\
\hline$A B \_628264$ & SNAP-25 & SC-20038 & Santa Cruz Biotechnology & Mouse & $1: 200$ & - & - \\
\hline NA & $\alpha$-synuclein & SNL-4 & CNDR & Rabbit & $1: 5000$ & $1: 1000$ & - \\
\hline NA & $\alpha$-synuclein & Syn303 & CNDR & Mouse & - & - & $1: 30,000$ \\
\hline NA & $\alpha$-synuclein & Syn7015 & CNDR & Mouse & - & - & $1: 1000$ \\
\hline NA & pS129- $\alpha$-synuclein & ab168381 & Abcam & Rabbit & $1: 1000$ & $1: 2000$ & $1: 2000$ \\
\hline NA & pS129- $\alpha$-synuclein & $81 \mathrm{~A}$ & CNDR & Mouse & - & $1: 5000$ & $1: 20,000$ \\
\hline NA & $\beta$-synuclein & Syn207 & CNDR & Mouse & $1: 200$ & - & - \\
\hline$A B \_223647$ & pSer202/pThr205 tau & AT8 & Thermo Fisher Scientific & Mouse & - & $1: 500$ & $1: 1000$ \\
\hline AB_1857785 & TBC1D10B & AV34521 & Sigma & Rabbit & $1: 1000$ & - & - \\
\hline AB_2313773 & neuronal $\beta$-tubulin & MMS-435P & Covance & Mouse & $1: 2000$ & - & - \\
\hline$A B \_477569$ & Tyrosine hydroxylase & T2928 & Sigma & Mouse & - & - & $1: 2000$ \\
\hline NA & Ubiquitin & $1 \mathrm{~B} 4$ & CNDR & Mouse & $1: 1000$ & $1: 1000$ & $1: 1000$ \\
\hline
\end{tabular}

${ }^{a}$ Antibodies used in this study, including Research Resource Identifiers (RRIDs) where available, and the dilutions used.

phosphorylation at serine 129 (pS129 $\alpha$-synuclein) is a diseasespecific modification found in LBs (Fujiwara et al., 2002) and glial cytoplasmic inclusions of MSA (Tu et al., 1998). In addition, components of protein degradation pathways, including ubiquitin and the autophagy adaptor p62 (sequestosome-1), are also sequestered in LBs (Kuzuhara et al., 1988; Lowe et al., 1988; Kuusisto et al., 2003). However, a large number of other proteins have also been found in LBs (Wakabayashi et al., 2013), but the role they play in LB pathogenesis is uncertain.

To identify protein pathways disrupted early in the disease process, we used a primary neuron culture model in which we reproducibly initiate endogenous $\alpha$-synuclein misfolding by adding $\alpha$-synuclein preformed fibrils (PFFs) to the culture (Volpicelli-Daley et al., 2011, 2014). This neuron model develops PD-like $\alpha$-synuclein inclusions and shows hallmark features of human LBs, including immunopositivity for pS129 $\alpha$-synuclein, ubiquitin, and p62.
Similar to studies of LBs isolated from human PD brains (Iwatsubo et al., 1996; Galvin et al., 1997; Baba et al., 1998), these $\alpha$-synuclein aggregates are resistant to mild detergent extraction, so they can be isolated biochemically. We took advantage of this biochemical feature in our neuron model to perform unbiased proteomic analysis of purified inclusion-associated proteins. We verified the identity of these proteins by extensive biochemical characterization in our neuron model as well as in postmortem human synucleinopathy brain tissue. We found that microtubule affinity-regulating kinases (MARKs) accumulated in the detergent-insoluble fraction of $\alpha$-synuclein PFF-treated neurons and in human synucleinopathy brain. An activated form of MARKs was detected only in neurons with LB-like inclusions in both our neuron culture model and in dopamine neurons of wildtype (WT) mice injected with $\alpha$-synuclein PFFs. Activated MARK also localized almost exclusively to LBs in human tissue and 
A

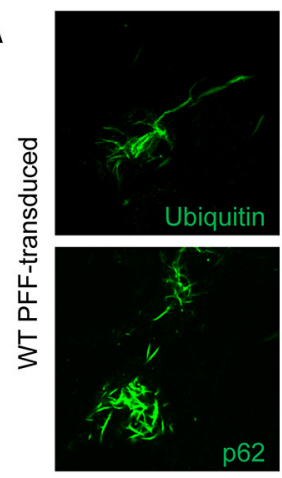

pS129 $\alpha$-synuclein Merge + MAP2 + DAPI
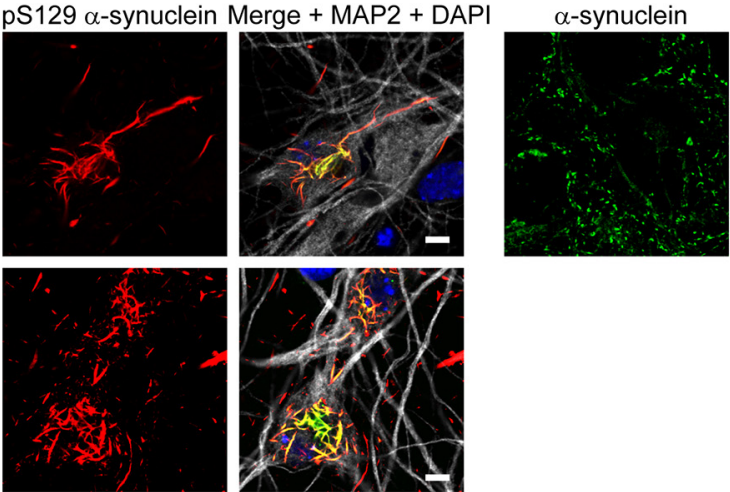

pS129 $\alpha$-synuclein Merge + MAP2 + DAPI
B

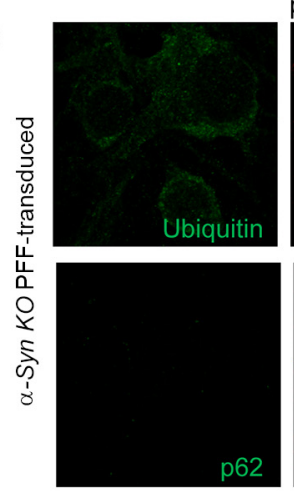

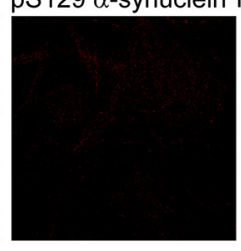
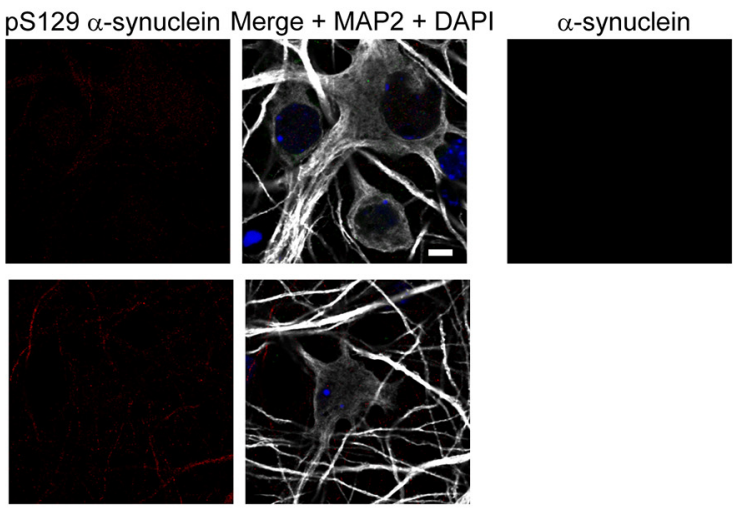

c

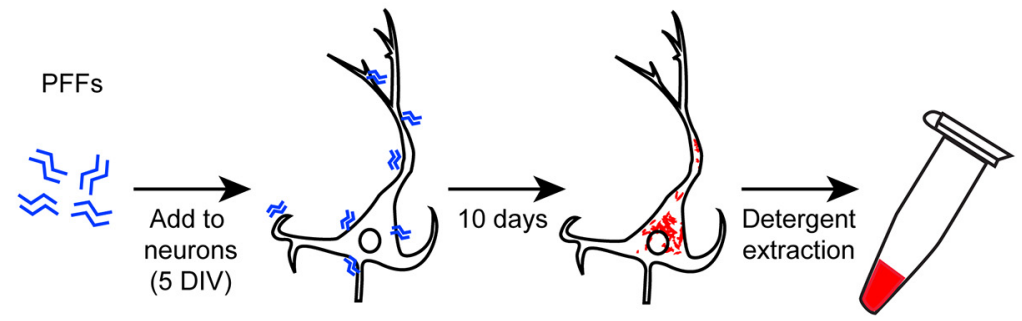

D

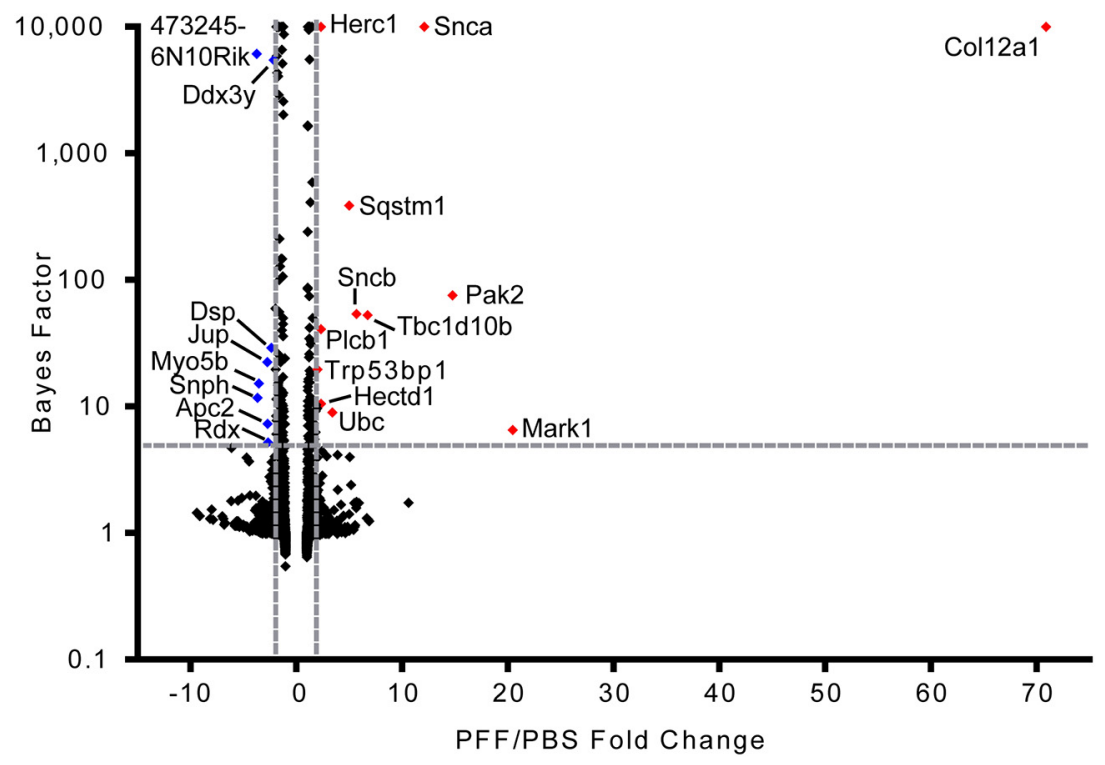

Figure 1. Proteomic screen reveals proteins sequestered in neuronal $\alpha$-synuclein inclusions. $\boldsymbol{A}$, Immunofluorescence performed on WT hippocampal neurons treated with $\alpha$-synuclein PFFs revealspS129 $\alpha$-synuclein inclusions (red) immunopositive for p62 and ubiquitin (green). The merge images MAP2 (gray) and DAPI stain (blue). Far right, $\alpha$-Synuclein immunofluorescence in was copurified biochemically with LBs as well. Further, inhibition of MARKs exacerbated $\alpha$-synuclein pathology in cultured neurons. We conclude that MARKs play a regulatory role early in the pathogenesis of synucleinopathies.

\section{Materials and Methods}

Animals. C57BL/6C3H F1 (strain 031), CD1 (strain 022) mice were obtained from Charles River. $S N C A^{-/-}$mice were bred in house after originally being obtained from the The Jackson Laboratory (B6;129X1-Sncatm1Rosl/J, stock \#003692). All housing, breeding, and procedures were performed according to the $\mathrm{Na}$ tional Institutes of Health Guide for the care and use of experimental animals and approved by the University of Pennsylvania Institutional Animal Care and Use Committee.

$\alpha$-Synuclein PFFs. Purification of recombinant $\alpha$-synuclein and generation of $\alpha$-synuclein PFFs was conducted as described extensively previously (Volpicelli-Daley et al., 2014).

Primary neuron cultures. Primary neuron cultures were prepared from E16-E18 CD1 and $S N C A^{-1-}$ mouse brains. Dissociated hippocampal neurons were plated at 17,000 cells/well (96well plate) 100,000 cells/well (24-well plate), or 1,000,000 cells/well (6-well plate). MARK kinase inhibitor (MKI, 39621 (454870), EMD Millipore) characterization has been previously described (Timm et al., 2011). MKI was diluted in DMSO, then diluted further in neuron media, and sonicated before application to enhance solubility. Neurons were either fixed with $4 \%$ PFA, $4 \%$ sucrose in PBS for immunocytochemistry or harvested via sequential detergent fractionation for biochemical analysis at the indicated time points. Immunostaining of neuronal cultures was performed as described previously (Volpicelli-Daley et al., 2014) with or without 1\% Triton X-100 extraction, as noted. Antibodies used for this study are listed in Table 1. Stained coverslips were mounted and imaged using a Leica TCS SP8 confocal microscope with LAS X software. MKI experiment was performed in black-walled 96-well plates and imaged on In Cell Analyzer 2200 (GE Healthcare) and analyzed in the accompanying software.

$\leftarrow$

these cultures. Scale bar, $5 \mu \mathrm{m}$. B, Immunofluorescence performed on $\alpha$-synuclein $K O$ neurons stained as in $A$ demonstrating a lack of ubiquitin, p62, and pS129 $\alpha$-synuclein inclusions in neurons lacking endogenous $\alpha$-synuclein (far right panel). Scale bar, $5 \mu \mathrm{m}$. C, Schematic of neuron culture model of synucleinopathy. Recombinant $\alpha$-synuclein PFFs (blue) are sonicated, diluted, and added to primary hippocampal neurons. After $10 \mathrm{~d}$, endogenous $\alpha$-synuclein (red) aggregates are sequentially extracted and subjected to mass spectrometry. $\boldsymbol{D}$, Volcano plot of the LC-MS/MS experiment peptide quantification. PFF/PBS ratio is plotted against Bayes factor. Dotted lines indicate cutoffs for fold change $(>2 \times)$ and Bayes factor $(>5)$. Colors indicate the level of change (black diamond represents unchanged; blue diamond represents decreased; red diamond represents increased), with changed proteins labeled with gene name. For details on the hits shown in the volcano plot, see Table 2. 
Table 2. Protein changes in proteomic screen ${ }^{a}$

\begin{tabular}{|c|c|c|c|c|c|c|c|c|c|}
\hline \multirow[b]{2}{*}{ Gene name } & \multirow[b]{2}{*}{ Protein name } & \multicolumn{6}{|c|}{ Peptide counts } & \multirow{2}{*}{$\begin{array}{l}\text { Normalized } \\
\text { fold change }\end{array}$} & \multirow{2}{*}{$\begin{array}{l}\text { Bayes factor } \\
\text { (PFF/PBS) }\end{array}$} \\
\hline & & PBS 1 & PBS 2 & PBS 3 & PFF 1 & PFF 2 & PFF 3 & & \\
\hline \multicolumn{10}{|l|}{ Increased } \\
\hline Col12a1 & Collagen alpha-1(XII) chain & 0 & 1 & 0 & 23 & 32 & 18 & 70.9 & $10,000.0$ \\
\hline Mark1 & MAP/microtubule affinity-regulating kinase 1 & 0 & 1 & 0 & 0 & 4 & 15 & 20.5 & 6.5 \\
\hline Pak2 & p21-activated kinase & 1 & 1 & 0 & 13 & 16 & 2 & 14.8 & 75.3 \\
\hline Snca & $\alpha$-synuclein & 21 & 35 & 45 & 383 & 442 & 461 & 12.1 & $10,000.0$ \\
\hline Tbc1d10b & TBC1 domain family, member 10B & 1 & 1 & 3 & 5 & 6 & 23 & 6.8 & 52.5 \\
\hline Sncb & $\beta$-synuclein & 2 & 3 & 1 & 9 & 15 & 11 & 5.7 & 53.8 \\
\hline Sqstm1 & Sequestosome-1 & 1 & 3 & 5 & 11 & 13 & 23 & 5.0 & 386.3 \\
\hline Ubc & Ubiquitin C & 10 & 0 & 0 & 10 & 5 & 17 & 3.4 & 9.0 \\
\hline Plcb1 & Phospholipase C, $\beta 1$ & 9 & 6 & 10 & 14 & 13 & 32 & 2.4 & 40.8 \\
\hline Herc1 & HECT and RLD domain containing E3 ubiquitin protein ligase family member 1 & 17 & 27 & 39 & 31 & 72 & 98 & 2.3 & $10,000.0$ \\
\hline Hectd1 & Hectd1 HECT domain containing 1 & 7 & 6 & 4 & 14 & 15 & 12 & 2.3 & 10.5 \\
\hline Trp53bp1 & Transformation-related protein 53 binding protein 1 & 1 & 6 & 21 & 6 & 17 & 36 & 2.0 & 19.6 \\
\hline \multicolumn{10}{|l|}{ Decreased } \\
\hline Ddx3y & DEAD (Asp-Glu-Ala-Asp) box polypeptide 3, Y-linked & 32 & 22 & 47 & 4 & 5 & 37 & -2.1 & 5458.8 \\
\hline Dsp & Desmoplakin & 21 & 19 & 8 & 4 & 5 & 11 & -2.3 & 29.0 \\
\hline $\operatorname{Rdx}$ & Radixin & 8 & 7 & 12 & 1 & 2 & 7 & -2.7 & 5.2 \\
\hline Apc2 & Adenomatosis polyposis coli 2 & 1 & 0 & 29 & 0 & 0 & 11 & -2.7 & 7.3 \\
\hline Jup & Junction plakoglobin & 15 & 13 & 10 & 1 & 1 & 11 & -2.7 & 22.4 \\
\hline Myo5b & Myosin VB & 6 & 9 & 15 & 0 & 0 & 8 & -3.5 & 15.1 \\
\hline Snph & Syntaphilin & 1 & 2 & 26 & 0 & 1 & 7 & -3.7 & 11.7 \\
\hline 4732456N10Rik & RIKEN CDNA 4732456N10 gene & 15 & 30 & 18 & 4 & 10 & 4 & -3.7 & 6093.3 \\
\hline
\end{tabular}

aProtein changes as detected by LC-MS/MS of the 1\% TX 100-insoluble fraction from primary hippocampal neurons treated with PBS or human WT $\alpha$-synuclein PFFs. Peptide counts from three independent experiments are represented. The proteins are ordered from largest increase to largest decrease. The fold change is representative of mean normalized PFF/mean normalized PBS.

Neuron sequential detergent fractionation. Proteins from primary neuronal cultures treated with PBS or $\alpha$-synuclein PFFs were sequentially extracted as described previously (Volpicelli-Daley et al., 2014). Briefly, neurons were scraped into 1 volume $1 \%$ Triton X-100 buffer, sonicated, and spun at $100,000 \times g$ for $30 \mathrm{~min}$. The pellet was sonicated and again spun at $100,000 \times g$ for $30 \mathrm{~min}$ in 1 volume $1 \%$ Triton $\mathrm{X}-100$ solution to remove remaining Triton X-100-soluble proteins. This pellet was suspended in 0.5 volumes $2 \%$ SDS solution, sonicated, and spun once more at $100,000 \times g$ for $30 \mathrm{~min}$. The first and final supernatant were kept for immunoblot analysis. For several proteins with low detectability in the $2 \%$ SDS fraction, the final $2 \%$ SDS suspension was done in 0.17 volumes to further concentrate proteins in this fraction.

Western blot analysis was performed using ImageStudio software. Values obtained from this program were normalized to average PBS values and statistical significance was calculated using a two-tailed Mann-Whitney test.

Clone 10 cell culture. Human embryonic kidney 293 cells stably expressing WT $\alpha$-synuclein have been described previously (Luk et al., 2009). Cells were cultured in DMEM (Invitrogen) supplemented with $10 \%$ FBS and $1 \times$ penicillin/streptomycin. Cells were plated at 30,000 cells $/ \mathrm{cm}^{2}$ the day before transfection. Transfection was achieved with FuGene HD transfection reagent (Promega) per manufacturer's instructions, and plasmid DNA. pcDNA3.1/V5-His Plk2 was a gift from Wafik El-Deiry (Addgene plasmid \#16015) (Burns et al., 2003). pCMV6 Mark1Myc-DDK was obtained from OriGene (catalog \#RC221556).

Cells were scraped in cell lysis buffer (25 mm Tris- $\mathrm{HCl}, \mathrm{pH}$ 7.6, $150 \mathrm{~mm}$ $\mathrm{NaCl}, 1 \mathrm{~mm}$ EDTA, 1\% NP-40, 5\% glycerol, protease and phosphatase inhibitors), sonicated, and cleared by centrifugation at $13,000 \times g$ for 10 min before suspension in $5 \times$ sample buffer.

Label-free spectral counting. The $2 \%$ SDS-soluble fractions of PBS- or $\alpha$-synuclein PFF-treated neurons were separated on a $10 \%$ Bis-tris gel and subjected to tandem liquid chromatography-mass spectrometry (LC-MS/MS) analysis as described previously (Min et al., 2014). Briefly, Coomassie-stained protein bands were excised from the gel, destained, reduced, alkylated, dehydrated, and trypsinized. Tryptic digests were analyzed by LC-MS/MS on a hybrid LTQ Orbitrap Elite mass spectrometer (Thermo Fisher Scientific) coupled with a nanoLC Ultra (Eksigent). LCMS/MS data were analyzed using Maxquant version 1.5.0.30 using the Uniprot complete mouse reference proteome. Because of assignment of identical spectra to different isoforms of the same protein, we combined spectral counts by gene name and manually collated multiple gene names for the same protein into a single comparison.

We developed two closely related mathematical models: an unregulated model that explains proteins that are unaffected in the $\alpha$-synuclein PFF-treated neurons, and a PFF-regulated model that explains proteins that are affected in the $\alpha$-synuclein PFF-treated neurons. We tested whether each protein's expression (as measured by the number of spectral counts) across treatment groups is better explained by the unregulated model or the $\alpha$-synuclein PFF-regulated model. The final output for each protein is a Bayes factor, which is the ratio of the probability that the protein is explained by the PFF-regulated model to the probability that the protein is explained by the unregulated model (i.e., a large Bayes factor means that the protein is differentially regulated by PFF treatment). The Bayes factor was calculated as described previously (Min et al., 2014), taking into account the mean number of spectral counts per run and protein length to minimize bias due to protein length and amount or instrument performance. We considered a protein to have significantly changed its expression levels across the control and experimental treatments if the number of spectral counts increased or decreased by at least 2 and it had a Bayes factor of at least 5 .

Stereotaxic injections. Injections of $\alpha$-synuclein PFFs were performed as previously described (Luk et al., 2012). Female mice were used for this study to allow rehousing after surgery. All the surgery or experiments were performed in accordance with protocols approved by the Institutional Animal Care and Use Committee of the University of Pennsylvania. Three female mice were injected when 2-3 months old. Mice were injected unilaterally by insertion of a single needle into the right forebrain (coordinates: $0.2 \mathrm{~mm}$ relative to bregma, $2.0 \mathrm{~mm}$ from midline) targeting the dorsal striatum ( $2.6 \mathrm{~mm}$ beneath the dura) and overlaying cortex ( 0.8 $\mathrm{mm}$ beneath the dura) with $5 \mu \mathrm{g} \alpha$-synuclein PFFs/site. Injections were done using a $10 \mu \mathrm{l}$ syringe (Hamilton) at a rate of $0.4 \mu \mathrm{l} / \mathrm{min}$. After 1 month, mice were perfused transcardially with PBS, and brains were removed and underwent overnight fixation in $70 \%$ ethanol in $150 \mathrm{~mm}$ $\mathrm{NaCl}, \mathrm{pH} 7.4$.

Immunohistochemistry/immunofluorescence. Brains from mice or human tissue that had been fixed in $70 \%$ ethanol in $150 \mathrm{~mm} \mathrm{NaCl}, \mathrm{pH} 7.4$, was subsequently processed into paraffin, mounted into paraffin blocks, and sectioned into $6 \mu \mathrm{m}$ sections for subsequent immunohistochemistry as previously described (Duda et al., 2000). Staining for immunohistochem- 


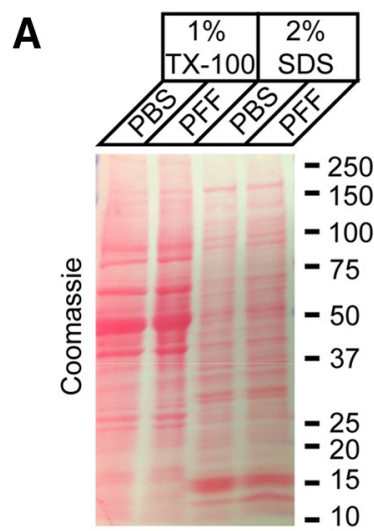

B

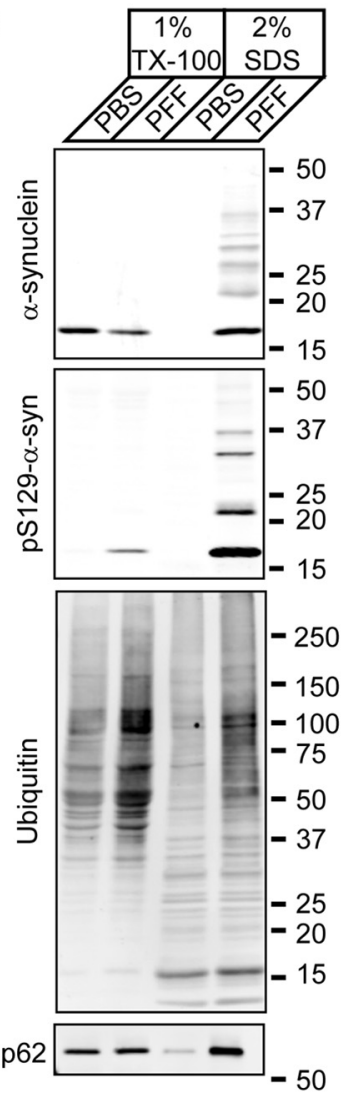

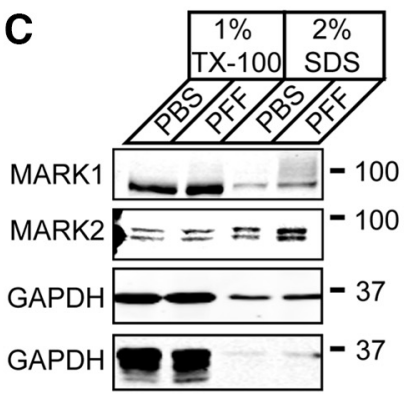

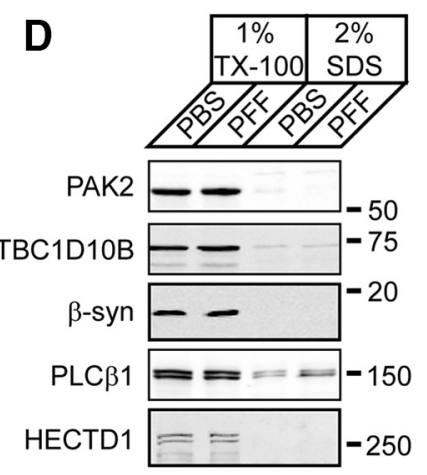

H
E

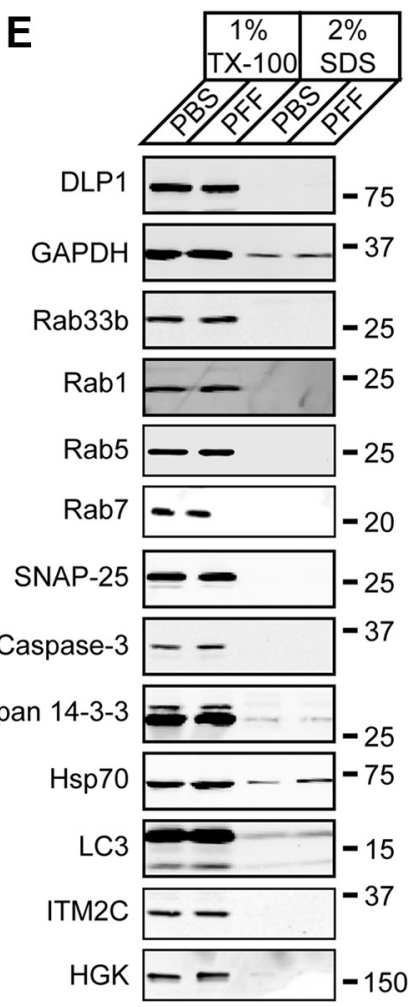

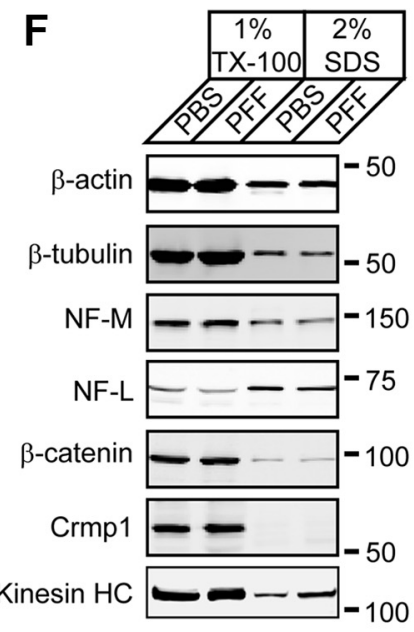

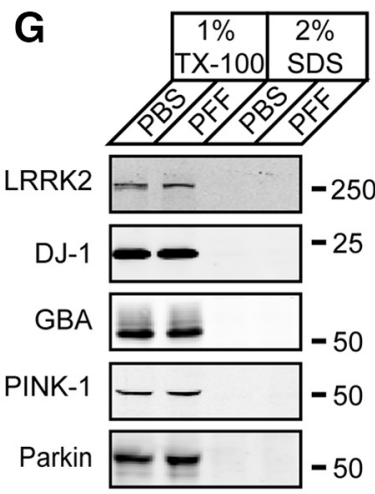

Figure 2. MARK1 and MARK2 are elevated in the insoluble fraction of $\alpha$-synuclein PFF-treated neurons. $A$, A representative Ponceau S-stained nitrocellulose membrane reveals the total amount of protein in the $1 \%$ Triton X-100- and 2\% SDS-soluble fractions of PBS and $\alpha$-synuclein PFF-treated neurons. B, Total and phosphorylated $\alpha$-synuclein, ubiquitin, and p62 are elevated in the $2 \%$ SDS-soluble fraction of PFF-treated neurons. C, MARK1 and MARK2 are also elevated in the Triton X-100-insoluble fraction of PFF-treated neurons. GAPDH immunoblots of samples used for MARK1 and MARK2 quantification are shown below. Because of low protein levels in the $2 \%$ SDS-soluble fractions, several proteins were blotted in samples containing $6 \times$ concentrated $2 \%$ SDS-soluble fractions (MARK1, MARK2, HGK, PAK2, Kinesin HC, Rab5, Rab7, PLCb1, ITM2C, TBC1D10B). D, Other proteins increased in the 2\% SDS-soluble PFF-treated fraction by mass spectrometry. As controls and for the purpose of characterization, a variety of other proteins were blotted, including signaling proteins $(\boldsymbol{E})$, trafficking and cytoskeletal proteins $(\boldsymbol{F})$, and PD-related proteins $(\boldsymbol{G})$. $\boldsymbol{H}$, Quantification of $2 \%$ SDS-soluble protein normalized to PBS-treated neurons ( $N \geq 3$ biological replicates for each protein). Data are mean \pm SEM. ${ }^{* *} p<0.01$ (tw0-tailed Mann-Whitney tests). ${ }^{*} p<0.05$ (two-tailed Mann-Whitney tests).

istry was done using DAB (Vector Laboratories) as a chromagen and AlexaFluor (Invitrogen)-conjugated antibodies for immunofluorescence.

Human brain sequential detergent fractionation. Frozen postmortem human cingulate gyrus brain tissue containing $\alpha$-synuclein-positive inclusions, and no tau-positive inclusions was selected for sequential extraction based on immunohistochemistry examination of these samples as described previously (Irwin et al., 2012) using previously established methods and matching for sex, age, and postmortem interval. These brains were sequentially extracted with increasing detergent strength as previously published (Guo et al., 2013). After thawing, meninges were removed and gray matter was carefully separated from white matter.
Gray matter was weighed and suspended in four volumes (w/v) high salt (HS) buffer (50 mм Tris-HCl, pH 7.4, 750 mм NaCl, $10 \mathrm{~mm} \mathrm{NaF,} 5$ mм EDTA, protease and phosphatase inhibitors), followed by homogenization with a Dounce homogenizer and centrifugation at $100,000 \times g$ for 30 $\mathrm{min}$. The HS wash was repeated and the resulting pellet was then homogenized with 9 volumes HS buffer with $1 \%$ Triton X-100 and centrifuged at $100,000 \times g$ for $30 \mathrm{~min}$. The pellet fraction was then homogenized with 9 volumes HS buffer with $1 \%$ Triton X-100 and 30\% sucrose and centrifuged at $100,000 \times g$ for $30 \mathrm{~min}$ to float away the myelin, which was discarded. The pellet was then homogenized with 9 volumes HS buffer with $1 \%$ Sarkosyl, rotated for $1 \mathrm{~h}$ at room temperature, and centrifuged at 


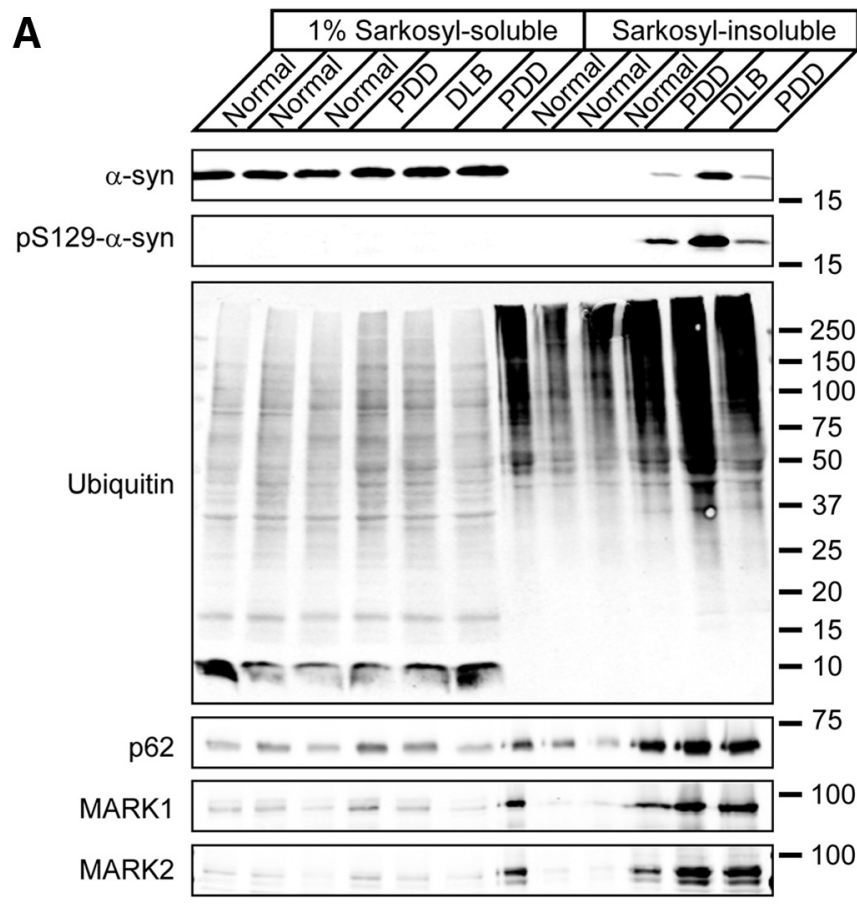

B

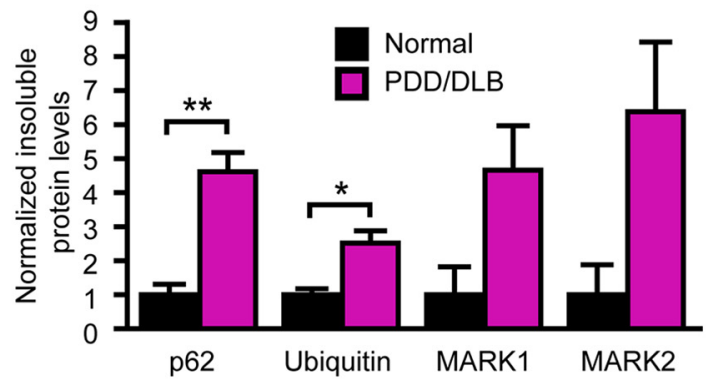

C

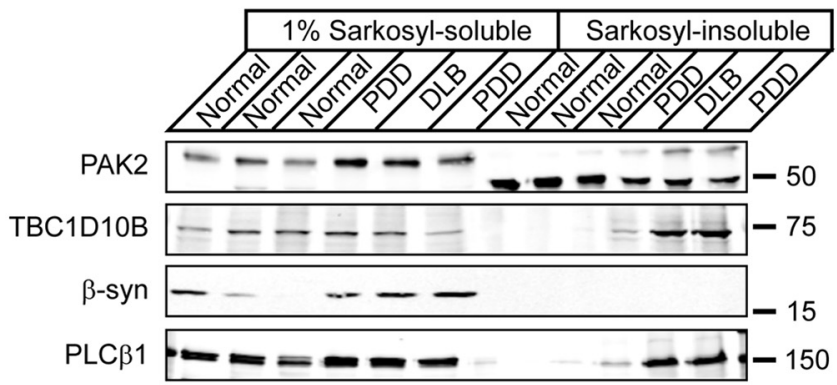

D

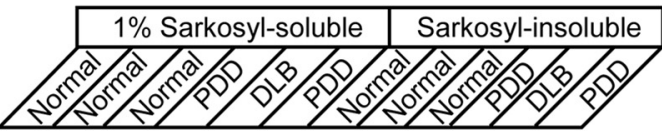

$\beta$-actin

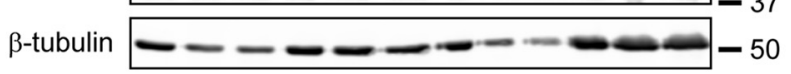

NF-M $\square-\infty-\infty-\infty-150$

$\mathrm{NF}-\mathrm{L} \equiv \equiv \equiv \equiv \equiv \equiv$

$\beta$-catenin $--\ldots-\cdots-100$

Kinesin HC $-----\cdots \cdots-\cdots$

E
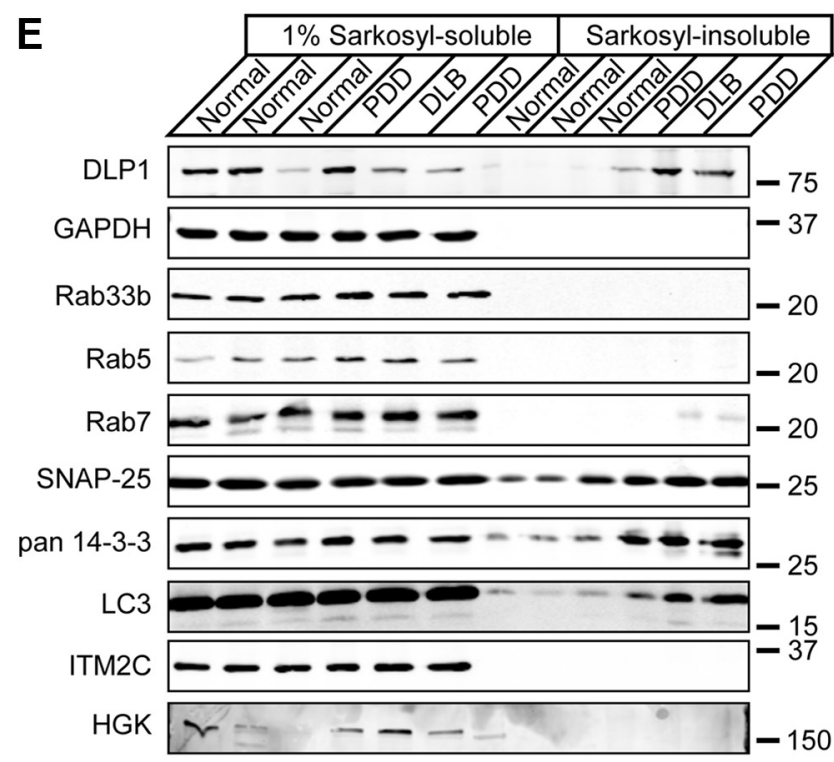

$\mathbf{F}$

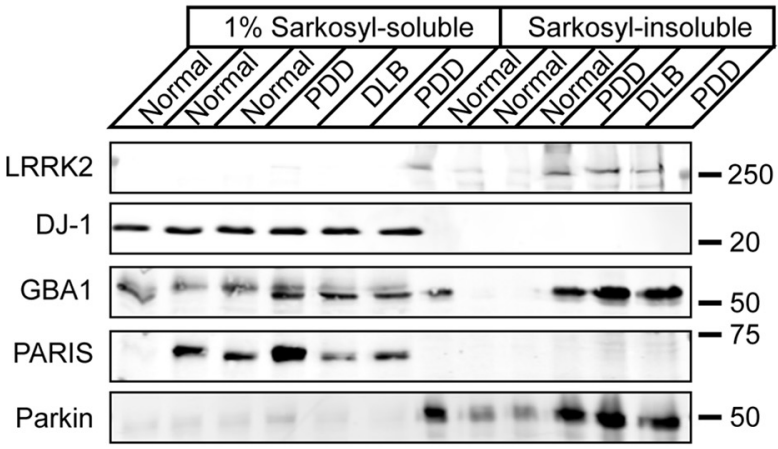

Figure 3. Proteins identified in neuronal culture model are insoluble in human synucleinopathy tissue. $A-F$, Cingulate gyrus tissue from PDD and DLB cases and age-matched controls lacking any $\alpha$-synuclein pathologies were sequentially extracted and combined into Sarkosyl-soluble and insoluble fractions. $\boldsymbol{A}$, Total and phosphorylated $\alpha$-synuclein, ubiquitin, p62, MARK1, and MARK2 proteins, which were elevated in our neuronal cell model, are also elevated only in the Sarkosyl-insoluble fraction of PDD and DLB patient tissues. B, Quantification of p62, ubiquitin, MARK1, and MARK2 immunoblotting is consistent with an increased insolubility of these proteins in PDD/DLB brains, although MARK1 and MARK2 levels show a high degree of variability. $C$, Other proteins that were increased in initial mass spectrometry experiments (Fig. 1B; Table 2) immunoblotted in patient tissue, with apparent increased insolubility of TBC1D10B and PLC $\beta$ 1. A variety of other proteins immunoblotted as a comparison with our neuron model of LBs confirm that many more proteins are altered in postmortem PDD/DLB human brain tissue, including a subset of cytoskeletal proteins (D), signaling proteins $(\boldsymbol{E})$, and PD-related proteins $(\boldsymbol{F})$. Data are mean \pm SEM. ${ }^{* *} p<0.01$ (two-tailed Mann-Whitney tests). ${ }^{*} p<0.05$ (two-tailed Mann-Whitney tests).

$100,000 \times g$ for $30 \mathrm{~min}$. The resulting pellet was then homogenized with $40 \mathrm{ml}$ DPBS with $1 \%$ Triton X-100 and centrifuged at $100,000 \times g$ for 30 min. The final pellet was resuspended in 0.25 volumes DPBS, sonicated, and stored at $-80^{\circ} \mathrm{C}$ pending biochemical analysis.

Statistical analysis. The statistical analysis for proteomic experiments is described separately. All other statistical analyses were done in GraphPad Prism. For comparisons with equal variance, as determined by an $F$ test, an unpaired Student's $t$ test was used. If the variances were found to be significantly different by an $F$ test, a Mann-Whitney test was performed.

\section{Results}

Proteomic screen of proteins sequestered in the insoluble fraction of $\alpha$-synuclein PFF-transduced neurons

We used a previously established method (Volpicelli-Daley et al., 2014) for inducing $\alpha$-synuclein PD-like pathology in WT hippocampal neurons followed by mass spectrometry of the $1 \%$ Triton X-100-insoluble fraction to determine which proteins become insoluble during $\alpha$-synuclein inclusion formation. This 
neuron culture system induces formation of inclusions that recapitulate major features of LBs in human synucleinopathies, including pS129 $\alpha$-synuclein inclusions that are positive for autophagy markers ubiquitin (Volpicelli-Daley et al., 2011) and p62 (Tanik et al., 2013) (Fig. 1A), in an endogenous $\alpha$-synuclein-dependent manner (Fig. 1B). Primary hippocampal neurons cultured for 5-6 d were treated with PBS (control) or human WT $\alpha$-synuclein PFFs. These neurons were then incubated for an additional $10 \mathrm{~d}$ post-treatment, after which they were fixed and immunostained or scraped for sequential detergent extraction (Fig. 1C).

Triplicate biological replicates of $1 \%$ Triton X-100-insoluble PBS- or PFF-treated neurons were analyzed by LC-MS/MS, and peptide assignments were combined by gene name to add power to the analysis by combining related isoforms of the same protein. We selected a cutoff of fold change $>2$ and a Bayes factor $>5$ for further analysis. From 6987 proteins initially identified, we found 20 were significantly changed, illustrating the relatively conservative changes that are occurring at this stage. Only 12 proteins were increased and 8 proteins decreased in the insoluble fraction of $\alpha$-synuclein PFF-treated neurons (Fig. 1D; Table 2). Among those increased, $\alpha$-synuclein (Snca), p62 (Sqstm1), and ubiquitin (Ubc) served as positive controls. The two peptides shared between $\alpha$ - and $\beta$-synuclein were increased in the $\alpha$-synuclein PFF-treated samples, whereas the one peptide unique to $\beta$-synuclein was not, decreasing the likelihood that $\beta$-synuclein coaggregates with $\alpha$-synuclein. Of the $\alpha$-synuclein peptides monitored, two were unique for murine $\alpha$-synuclein and these showed an elevation in the $\alpha$-synuclein PFF-treated fraction of 3.2- and 7.9-fold, indicating the ability of this method to detect aggregated endogenous mouse $\alpha$-synuclein. Several other proteins of interest were increased in the $\alpha$-synuclein PFF-treated insoluble fraction compared with PBS treatment, including extracellular matrix protein collagen XII A1 (70.9-fold) and microtubule affinity-regulating kinase 1 (MARK1, 20.5-fold).

MARK1 and MARK2 are increased in the insoluble fraction of PFF-treated neurons

To confirm mass spectrometry findings, we conducted Western blotting on all proteins that showed an increase by peptide analysis in addition to many proteins that did not show any difference as a con-
A

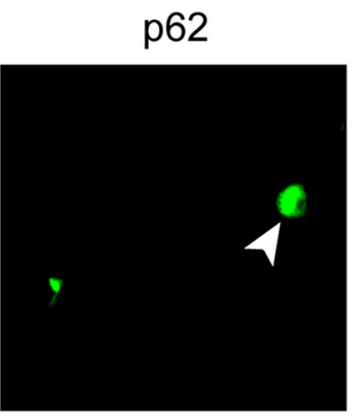

pS129- $\alpha-s y n$

Merge + DAPI
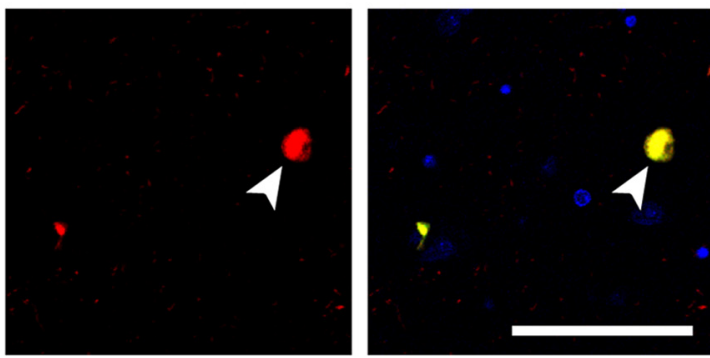

B

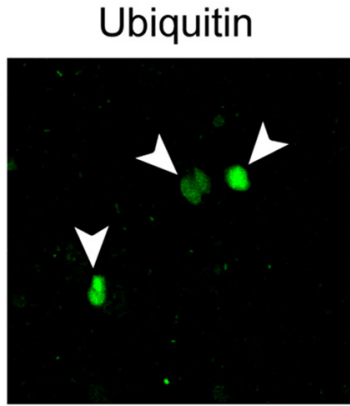

pS129- $\alpha-s y n$

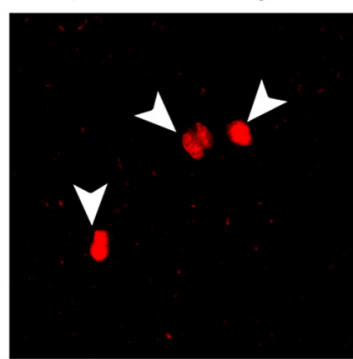

Merge + DAPI

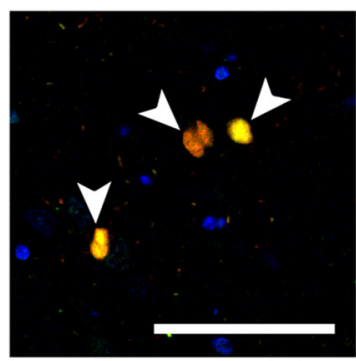

C
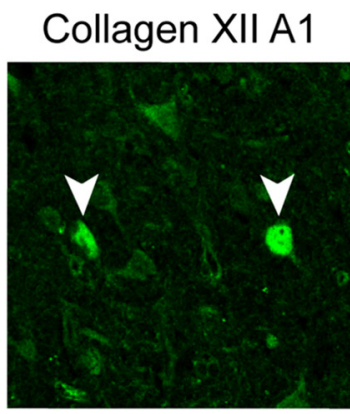

Syn303

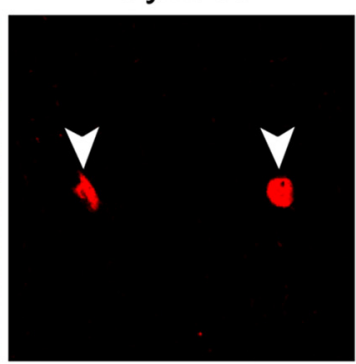

Merge + DAPI

D

MARK1

Syn303
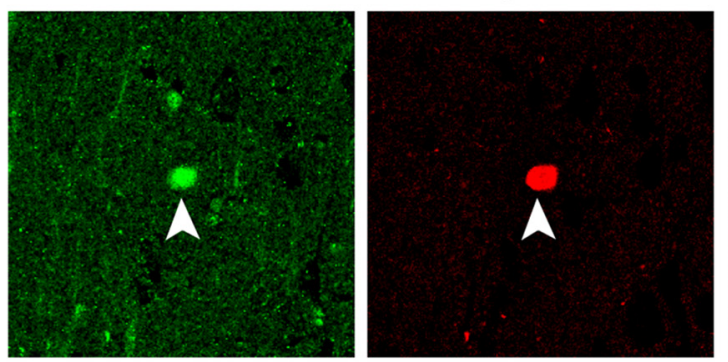

Merge + DAPI

E

MARK2

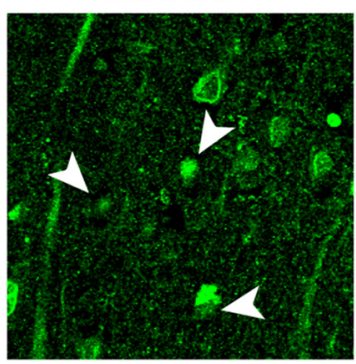

Syn303
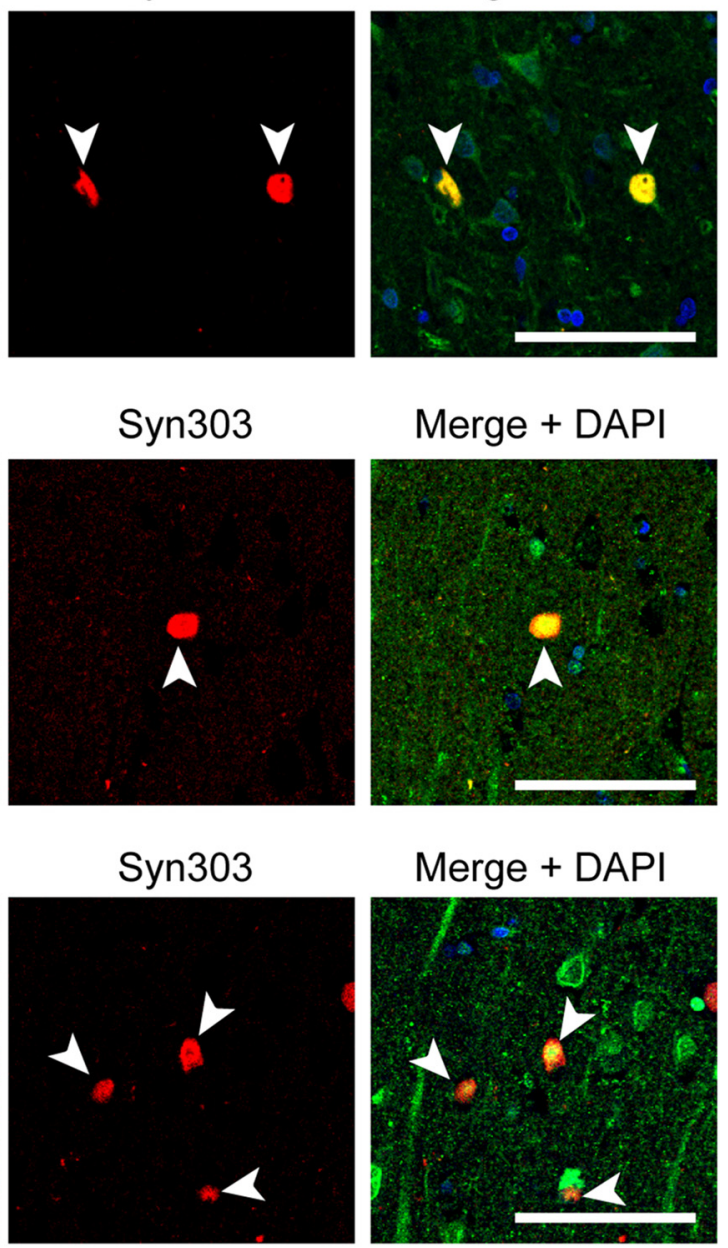

Merge + DAPI

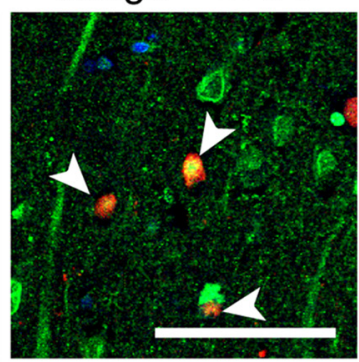

Figure 4. MARK1 and MARK2 show partial localization in LBs in human synucleinopathy brains. $\boldsymbol{A}-\boldsymbol{E}$, Paraffin-embedded ethanol-fixed tissue from DLB patients immunostained for the proteins of interest. Double-label immunofluorescence allows for the visualization of pS129 or misfolded $\alpha$-synuclein (Syn303, red) with p62 (A), ubiquitin (B), collagen XII A1 (C), MARK1 (D), and MARK2 (E), White arrowhead represents LBs. Scale bars, $75 \mu \mathrm{m}$. 
A

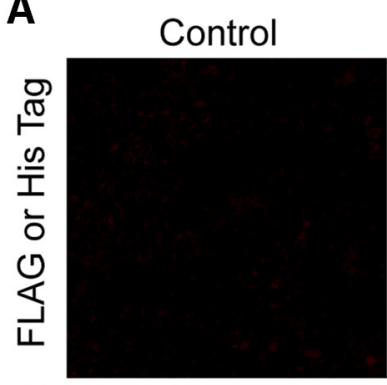

MARK1-Myc-DDK
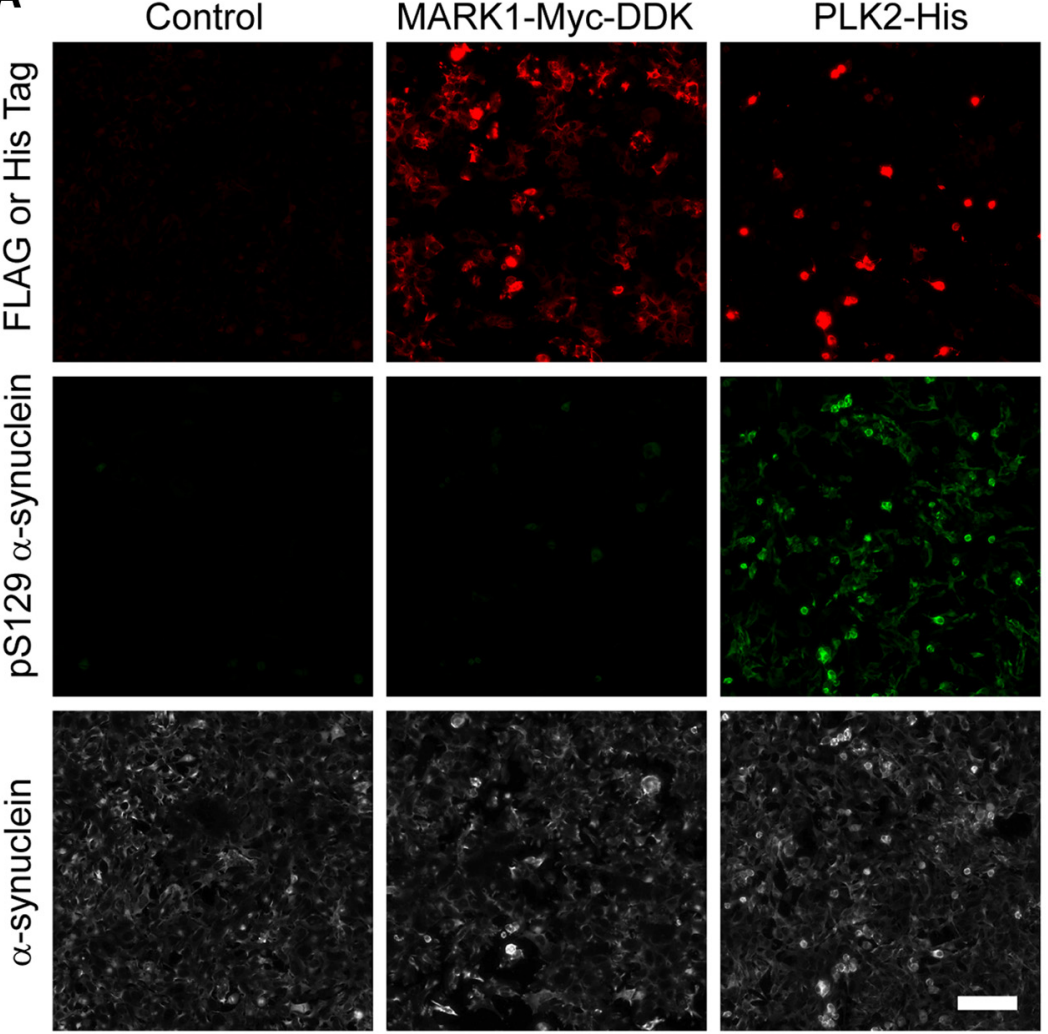

B

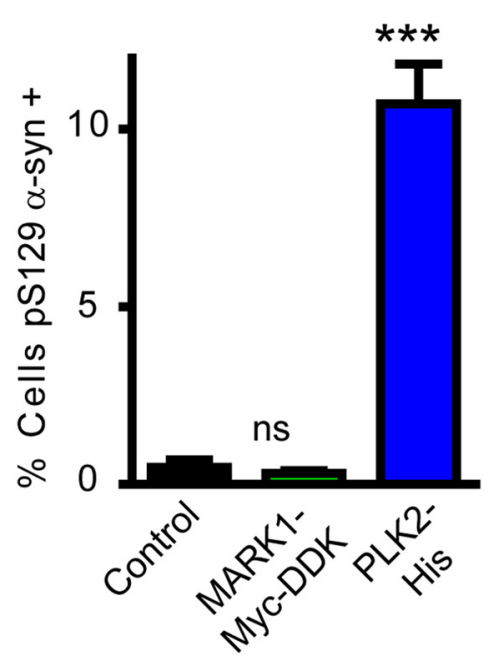

C

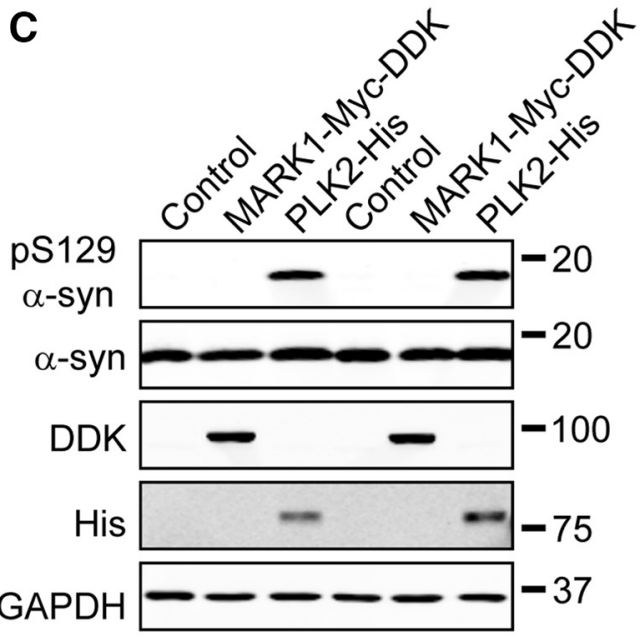

Figure 5. MARK1 does not phosphorylate $\alpha$-synuclein. Transfection of plasmids expressing Mark1-Myc-DDK or Plk2-His into HEK293 cells stably overexpressing human WT $\alpha$-synuclein allow for the assay of pS129 $\alpha$-synuclein phosphorylation by immunofluorescence $(\boldsymbol{A})$ and Western blot (B). $\boldsymbol{A}$, Overexpression of MARK1-Myc-FLAG and PLK2-His is visualized using antibodies directed against their respective tags. $\alpha$-Synuclein can be seen in all three conditions, but phosphorylated $\alpha$-synuclein is only seen with transfection of PLK2-His. The number of cells positive for pS129 $\alpha$-synuclein is quantified in B. C, Cells expressing the same constructs were lysed, and proteins were visualized by Western blot ( $N=3$ biological replicates). Scale bars: $A, 100 \mu \mathrm{m}$. Data are mean \pm SEM. ${ }^{* * *} p<0.001$ (two-tailed $t$ test).

trol for the cell culture model. No dramatic differences are evident by Ponceau S protein stain (Fig. 2A), and the large majority of proteins blotted showed no difference between PBS- and $\alpha$-synuclein PFF-treated neurons, validating the specificity of insoluble inclusion formation. We confirmed specific accumula- tion of $\alpha$-synuclein, pS129 $\alpha$-synuclein, p62, and ubiquitin (Fig. 2B) in PFF-treated neurons, indicating an accumulation of endogenous $\alpha$-synuclein and autophagy markers. In addition, we confirmed that MARK1 and related family member MARK2, which shares several of the peptides identified by LC-MS/MS, were increased in the insoluble fraction of $\alpha$-synuclein PFF-treated neurons (Fig. 2C). Interestingly, MARK1 immunoblotting reveals a ladder of MARK1 that is not present in PBS-treated neurons. These were the only significant changes we detected in our samples by Western blot, including those that were changed by LCMS/MS (Fig. 2D, H), although analysis of several of these proteins was precluded by low or no detection by antibodies. We confirmed many proteins that were found to be unchanged by LC-MS/MS, including signaling proteins (Fig. 2E), cytoskeletal proteins (Fig. $2 F$ ), and proteins mutated in familial Parkinsonism (Fig. $2 G)$.

Insoluble proteins in the neuron model of LB formation are also insoluble in human disease brains and localized to LBs

During PD/PDD/DLB pathogenesis, patients accumulate insoluble aggregates of phosphorylated $\alpha$-synuclein in LBs and markers of autophagy ubiquitin and p62 (Wakabayashi et al., 2013). Because the PD-like aggregates in $\alpha$-synuclein PFFtreated neurons also accumulate ubiquitin and p62, we performed sequential detergent extraction on cingulate gyrus from PDD, DLB, and age-matched controls to determine whether MARKs accumulate in human LBs. Tissue was screened for a high abundance of LBs and no or scant phospho-tau or amyloid $\beta$ accumulations, whereas age-matched control cingulate tissue was selected for the absence of any LB, tangle, or plaque pathologies. Immunoblot analysis on the $1 \%$ Sarkosylsoluble and Sarkosyl-insoluble fractions showed pS129 $\alpha$-synuclein accumulated in the insoluble fraction from PDD and DLB but not control cases (Fig. $3 A, B$ ). In addition, the autophagy-linked proteins ubiquitin and 062 and kinases MARK1 and MARK2 (Fig. $3 A, B$ ) also showed increased accumulation in the insoluble fraction of human synucleinopathy brains, although there is significant variability in the MARK1 and MARK2 levels in these samples. TBC1D10B and PLC $\beta 1$, which were identified in our original mass spectrometry experiment, also accumulate in PDD/DLB tissue (Fig. 3C). Given previous reports of proteins accumulated in the insoluble fraction of human synucleinopathy 
A

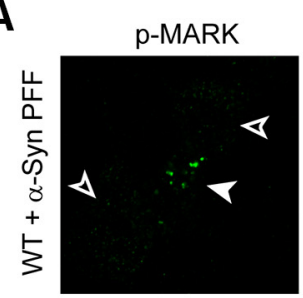

pS129- $\alpha$-synuclein Merge + MAP2/DAPI
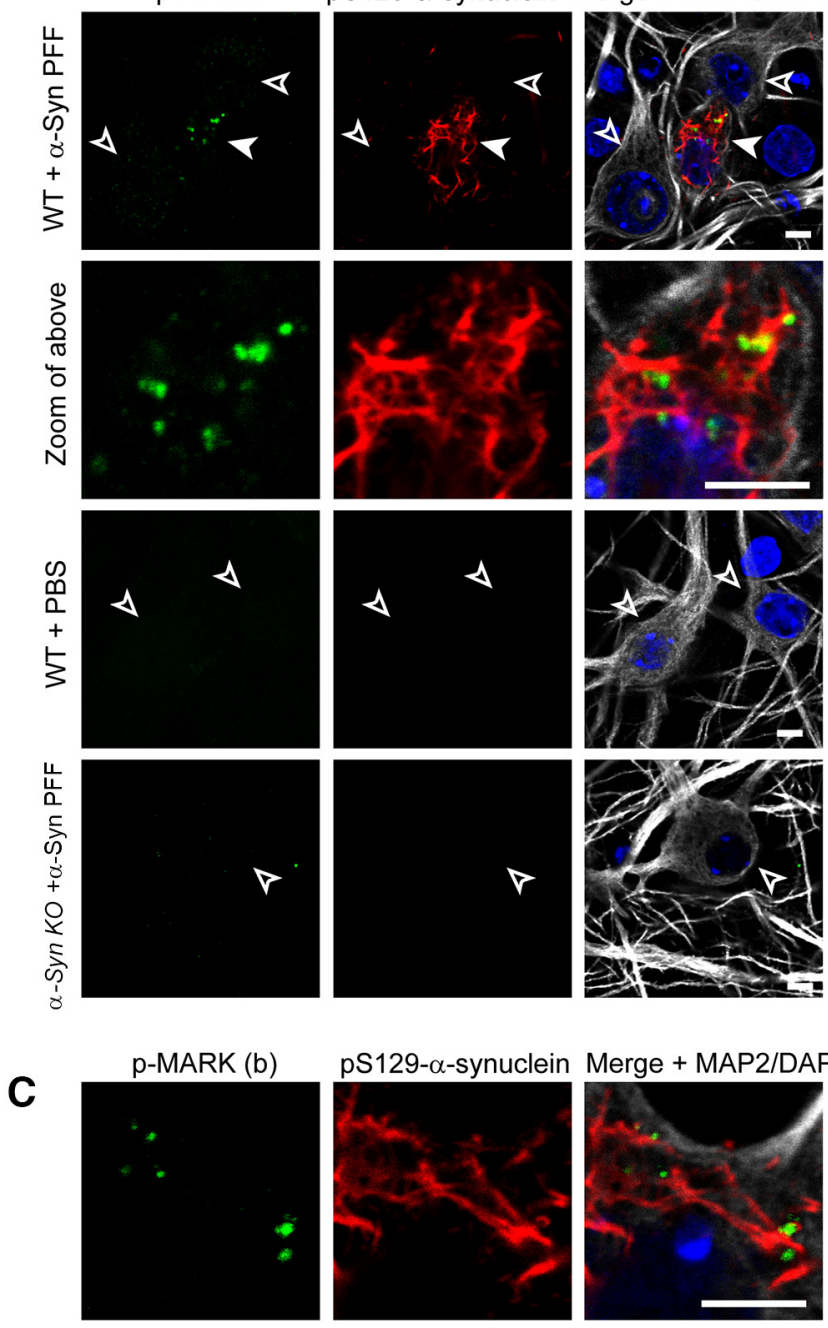

D
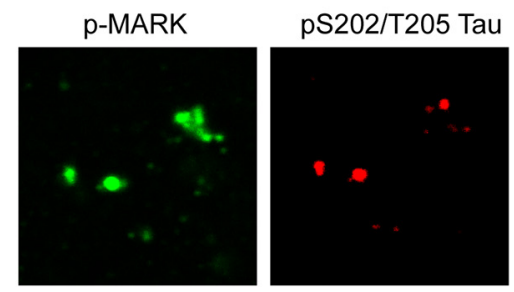

E

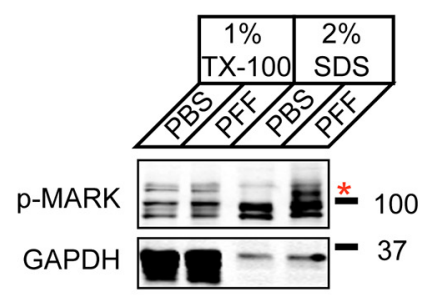

$\mathbf{F}$

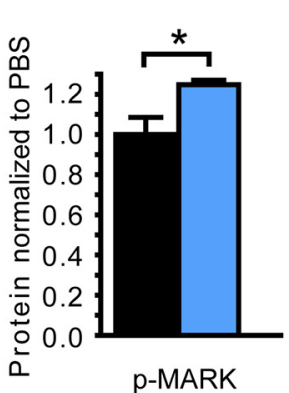

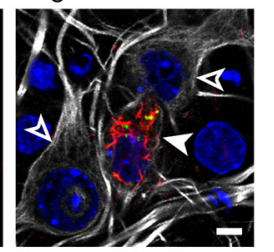
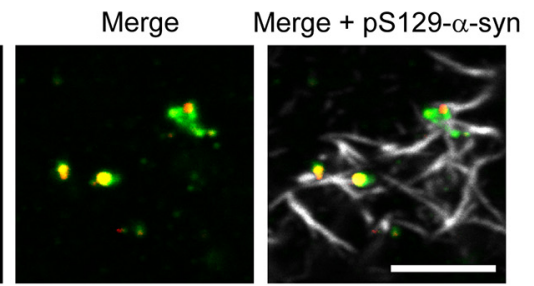

B

p-MARK $(-) /$ p- $\alpha$-syn (-)

p-MARK $(+) l$ p- $\alpha$-syn (-)

p-MARK $(+) l$ p- $\alpha$-syn (+)
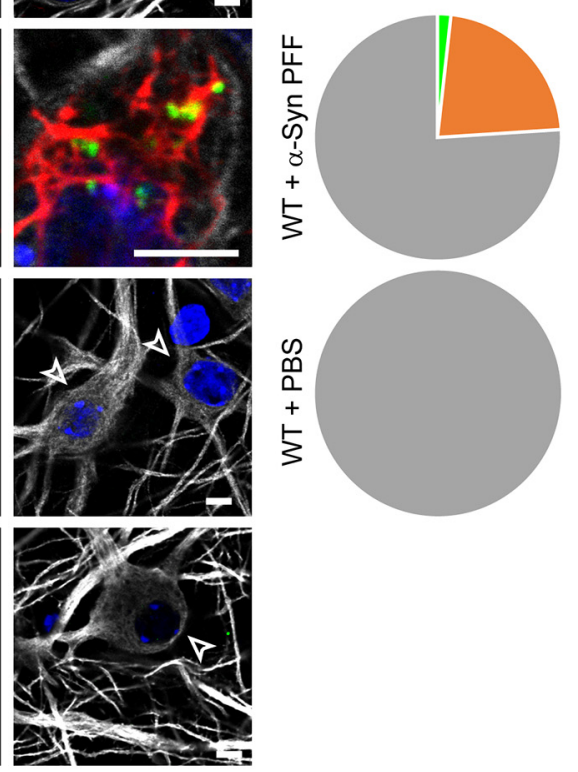

G

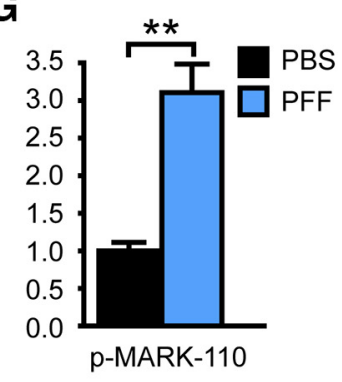

Figure 6. Active MARK is localized to $\alpha$-synuclein inclusions in neurons. $A$, Immunofluorescence of p-MARK (green), pS129 $\alpha$-synuclein (red), MAP2 (gray), and DAPI (blue) in hippocampal neurons transduced with $\alpha$-synuclein PFFs and fixed $10 \mathrm{~d}$ after transduction. Row 1 has three WT neuron cell bodies, only one of which is positive for pS129 $\alpha$-synuclein and is also positive for p-MARK. Row 2 is a higher magnification of the neuron in Row 1. Rows 3 and 4 show PBS-treated WT and $\alpha$-synuclein PFF-treated $\alpha$-synuclein KO neurons, respectively, which show a similar lack of p-MARK and pS129 $\alpha$-synuclein staining. White (open) arrowhead represents neuron cell bodies without $\alpha$-synuclein inclusions. White (solid) arrowhead represents $\alpha$-synuclein inclusionbearing neuron, which also has p-MARK immunopositivity. $\boldsymbol{B}$, Quantification of the percentage of neurons that

tissue, we proceeded to immunoblot our samples for cytoskeletal proteins (Fig. $3 D$ ), signaling proteins (Fig. $3 E$ ), and proteins implicated in familial forms of PD (Fig. $3 F)$. Several of these proteins, including all cytoskeletal proteins tested, DLP1, 14-3-3, LC3, leucine-rich repeat kinase 2, GBA1, and Parkin, exhibit an increased distribution in the insoluble fraction of synucleinopathy brains compared with age-matched controls. These results are consistent with our rationale of using a cell model to minimize accumulation of proteins unrelated to disease pathogenesis.

Given these findings, we immunostained cingulate gyrus from DLB and PDD brains with antibodies for $\alpha$-synuclein and other proteins of interest to determine whether they were enriched in LBs. As previously reported (Kuzuhara et al., 1988; Lowe et al., 1988; Kuusisto et al., 2003), p62 and ubiquitin showed high colocalization with $\alpha$-synuclein in LBs (Fig. $4 A, B$ ). We were also able to use an antibody for collagen XII A1, the protein that showed the most dramatic difference in cells by mass spectrometry (Fig. 1C), to visualize an increased localization of this protein to LBs, although there was abundant collagen XII A1 immunoreactivity throughout the section (Fig. 4C). MARK1 and MARK2 showed a similar pattern with staining throughout the tissue section, including in LBs (Fig. 4D,E).

\section{MARK1 does not phosphorylate \\ $\boldsymbol{\alpha}$-synuclein}

Given the role of MARK1 as a serine/threonine kinase, and the phosphorylation of $\alpha$-synuclein at S129 that is a hallmark of pathological $\alpha$-synuclein PD/PDD/DLB

$\leftarrow$

were $\mathrm{pS} 129 \alpha$-synuclein ${ }^{-} / \mathrm{p}$-MARK ${ }^{+}$or $\mathrm{p}$-MARK ${ }^{+} / \mathrm{p}-\alpha$ synuclein ${ }^{+}$. No neurons were found that were pS129 $\alpha$-synuclein ${ }^{+}$, but not $\mathrm{p}^{- \text {MARK }^{+}(n=171 \text { neurons }}$ $\alpha$-synuclein PFF-transduced, $n=106$ neurons PBS-treated from three independent experiments each). C, WT hippocampal neurons treated with $\alpha$-synuclein PFFs, but stained with a second p-MARK antibody (p-MARK(b)), show a similar staining pattern as in $\boldsymbol{A} . \boldsymbol{D}$, Immunofluorescence of similarly treated neurons as in $\boldsymbol{A}$ but stained with p-MARK, pS202/T205 tau (AT8), and pS129 $\alpha$-synuclein to indicate the juxtaposition of p-MARK and AT8 puncta within a neuron with pathological $\alpha$-synuclein. $\boldsymbol{E}$, Immunoblotting of p-MARK in sequentially extracted PBS or PFF-treated neuron samples. Red asterisk indicates an $\sim 110 \mathrm{kDa}$ band that shows special enhancement in the PFF-treated samples. Immunoblot of GAPDH for these samples is shown below. $\boldsymbol{F}$, Quantification of p-MARK in extracted neuron samples ( $N=4$ biological replicates). $G$, Quantification of the $110 \mathrm{kDa}$-MARK band in extracted neuron samples ( $N=4$ biological replicates). Scale bars, $5 \mu \mathrm{m}$. Data are mean \pm SEM. ${ }^{* *} p<0.01$ (two-tailed $t$ tests). ${ }^{*} p<0.05$ (two-tailed $t$ tests). 
A

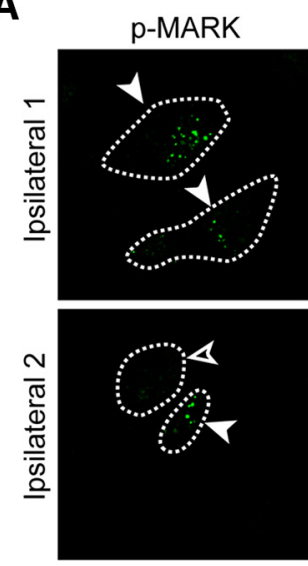

pS129- $\alpha$-synuclein
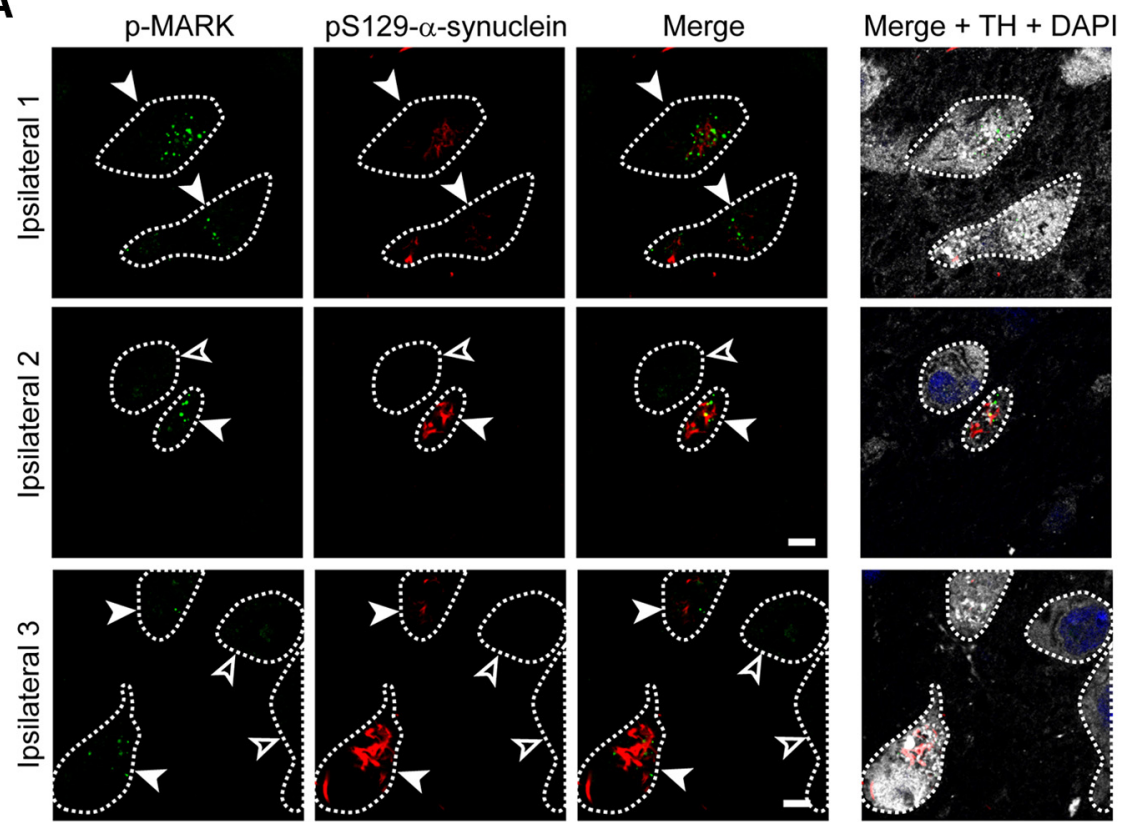

B
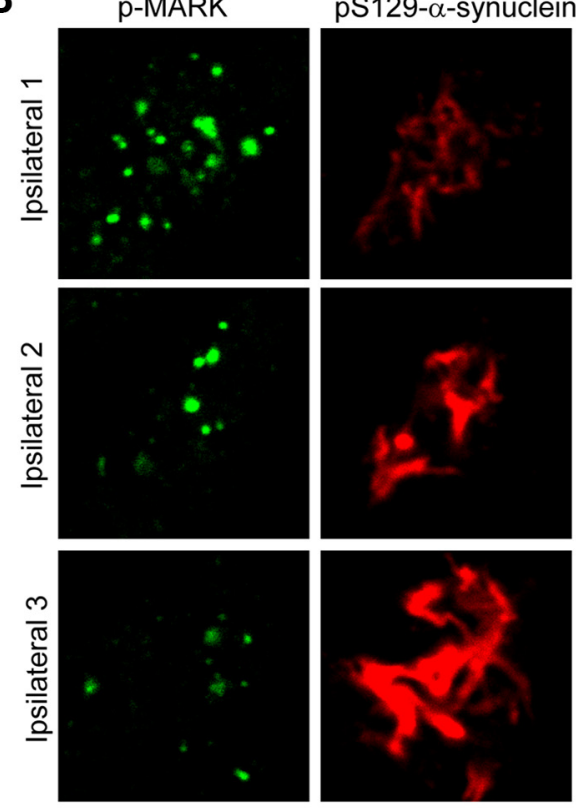

C

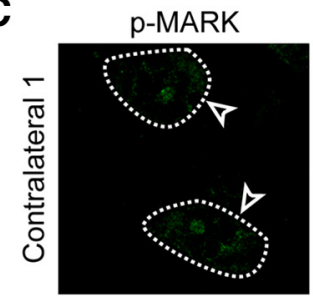

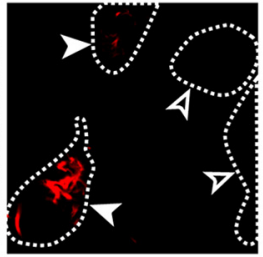

pS129- $\alpha$-synuclein
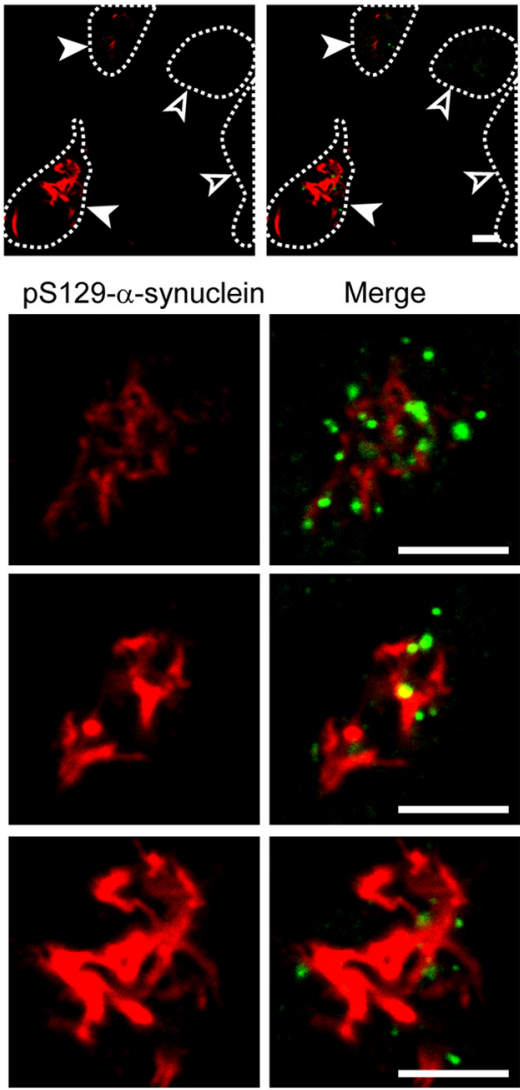

pS129- $\alpha$-synuclein

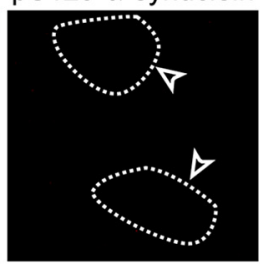

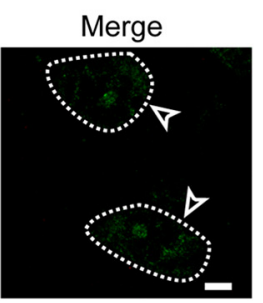

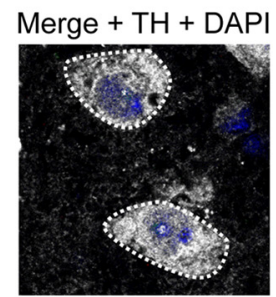

Figure 7. Active MARK is localized to $\alpha$-synuclein inclusions in mouse dopamine neurons. A, Immunofluorescence of p-MARK and pS129 $\alpha$-synuclein within TH-positive neurons of the substantia nigra. The outlines indicate TH-positive cell bodies. Neurons with pS129 $\alpha$-synuclein inclusions in 3 mice also have p-MARK reactivity, whereas those without $\alpha$-synuclein inclusions do not. $\boldsymbol{B}$, Three neurons from the mice shown in $\boldsymbol{A}$ are shown at increased magnification. $\boldsymbol{C}$, TH-positive neurons contralateral to the injection site in one mouse have neither $\alpha$-synuclein nor p-MARK immunoreactivity. White (open) arrowhead represents neuron cell bodies without $\alpha$-synuclein inclusions. White (solid) arrowhead represents $\alpha$-synuclein inclusion-bearing neuron, which also has p-MARK immunopositivity. Scale bars, $5 \mu \mathrm{m}$.

and related synucleinopathies, we tested whether MARK1 is able to phosphorylate $\alpha$-synuclein. Polo-like kinase 2 (PLK2) has previously been shown to robustly phosphorylate $\alpha$-synuclein and was used as a positive control for $\alpha$-synuclein phosphorylation in this study. HEK293 cells stably expressing human WT $\alpha$-synuclein were treated with transfection reagent alone (control), Mark1-Myc-DDK, or Plk2-His cDNA. Both of the constructs expressed the protein of interest as indicated by staining with $\alpha$-FLAG or $\alpha$-His antibodies (Fig. 5A). PLK2 was able to phosphorylate $\alpha$-synuclein robustly, whereas MARK1 was not able to phosphorylate $\alpha$-synuclein above background levels despite the presence of abundant $\alpha$-synuclein expression (Fig. $5 A, B$ ). Western blots of cell lysates from cells overexpressing $\alpha$-synuclein and MARK1 or PLK2 confirmed that pS129 $\alpha$-synuclein was present only when PLK2-His was expressed (Fig. 5C).

\section{Active MARK is accumulated in $\alpha$-synuclein PFF-treated neurons and mouse tissue}

Our initial immunoblot studies of MARK1 revealed a higher molecular weight ladder in PFF-treated primary neuron cultures (Fig. $2 C)$. Activated MARK, as identified by phosphorylation in the activation loop at threonine 215 in MARK1, has been implicated in neurodegenerative diseases (Lund et al., 2014). We used an antibody generated against this phospho-epitope in MARK1, MARK2, and MARK3 to probe primary hippocampal neurons. Small, p-MARK-positive puncta are present in neurons harboring perikaryal pS129 $\alpha$-synucleinpositive inclusions but not in neurons in the same cultures without $\alpha$-synuclein inclusions (Fig. 6A,B), in neurons treated with PBS (Fig. $6 A, B$ ), or $\alpha$-synuclein $K O$ neurons (Fig. 6A). Blinded scoring of these neurons found that $24 \%$ of neurons contained p-MARK puncta (41 of 171), whereas nearly all of those had pS129 $\alpha$-synuclein positive perikaryal inclusions (38 of 171) (Fig. 6B, 30 images from three independent experiments). We did not find any pS129 $\alpha$-synuclein cell body inclusions that did not have associated p-MARK puncta ( 0 of 38) and no neurons treated with PBS had either p-MARK or pS129 $\alpha$-synuclein staining (Fig. 6B; 0 of 106, 15 images from three independent experiments), supporting a direct correlation between these two phosphorylated proteins. We further confirmed the specificity of the p-MARK staining by using a separate antibody generated against the 
A
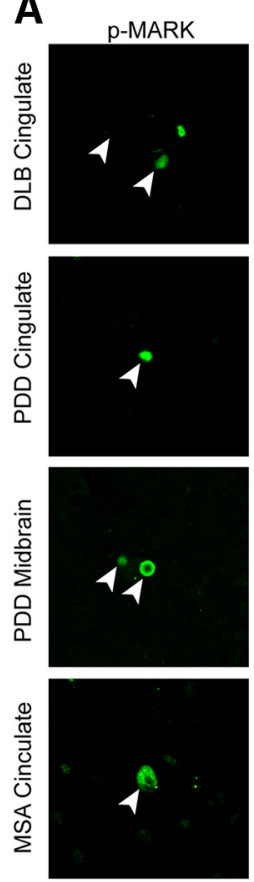

B

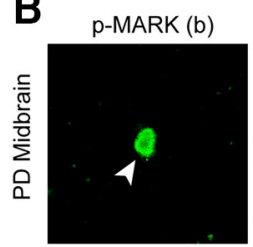

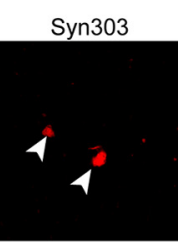
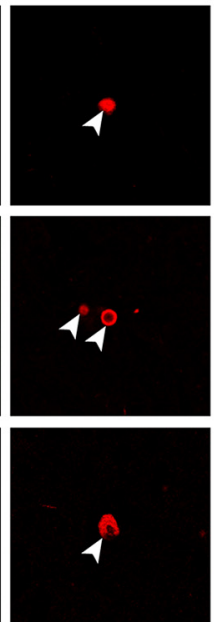

Syn303

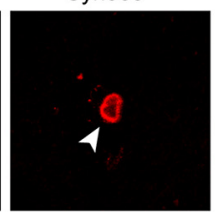

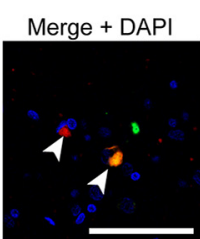
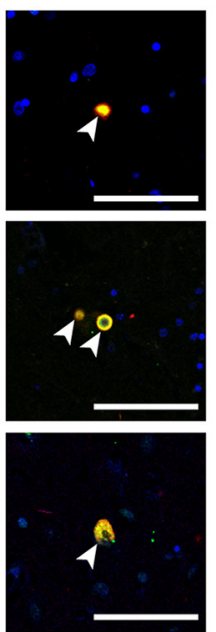

Merge + DAPI

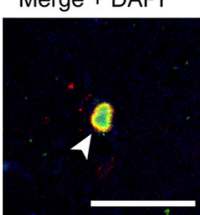

C

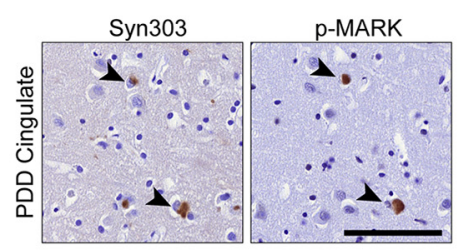

D
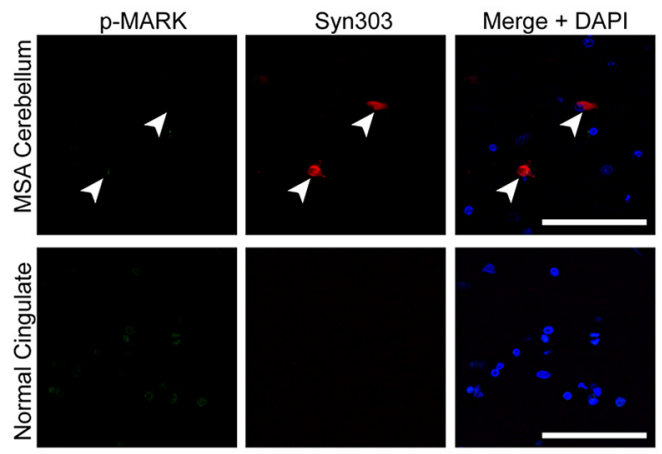

E

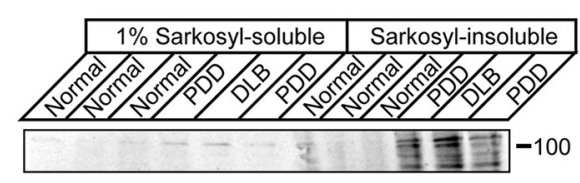

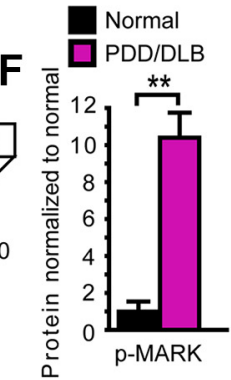

Figure 8. Active MARK is localized in $\alpha$-synuclein inclusions in human synucleinopathies. $\boldsymbol{A}$, Tissue of subjects with neurodegenerative synucleinopathies was immunostained for p-MARK (green) and misfolded $\alpha$-synuclein (Syn303, red). White arrowhead represents LBs. B, LBs in PD midbrain tissue stained with a second p-MARK antibody (p-MARK(b)) show a similar staining pattern as in A. C, Immunohistochemistry of misfolded $\alpha$-synuclein (Syn303) and p-MARK in adjacent sections further reveals that these two proteins are in the same neurons. $\boldsymbol{D}$, Neither glial cytoplasmic inclusions (white arrowhead) in MSA cerebellar white matter nor cingulate gyrus from normal human brain has accumulations of p-MARK. $\boldsymbol{E}$, Cingulate gyrus tissue from PDD and DLB cases and age-matched controls was sequentially extracted and combined into Sarkosyl-soluble and insoluble fractions. p-MARK immunoblot is shown. $\boldsymbol{F}$, Quantification of the immunoblotting in $\boldsymbol{E}$. Scale bars: $\boldsymbol{A}, \boldsymbol{B}, \boldsymbol{D}, 75 \mu \mathrm{m} ; \boldsymbol{C}, 100 \mu \mathrm{m}$. Data are mean \pm SEM. ${ }^{* *} p<0.01$ (two-tailed $t$ test).

same epitope (p-MARK(b); Fig. 6C). Costaining with a pS202/ T205 tau antibody (AT8) revealed that the activated MARK puncta were juxtaposed with p-tau staining (Fig. 6D), which we interpret to signify that activated MARK is phosphorylating its substrate tau. The p-MARK antibody reveals several bands by Western blot, comprising phosphorylated forms of MARK1, MARK2, and MARK3. Sequentially extracted neurons have $\sim 24 \%$ increase in total p-MARK levels in the $2 \%$ SDS-soluble fraction (Fig. 6E, F) This difference is largely accounted for by an $\sim 110 \mathrm{kDa}$ band, which is increased more than threefold in $\alpha$-synuclein PFF-treated neurons (Fig. 6G) and may constitute a specific isoform or post-translationally modified MARK protein.

To determine whether alterations in p-MARK were also present in vivo, we performed studies on WT mice injected with WT mouse $\alpha$-synuclein PFFs as previously described (Luk et al., 2012). We conducted immunofluorescence on mice 1 month after intrastriatal and cortical injection of $\alpha$-synuclein PFFs. Injection of $\alpha$-synuclein PFFs in this model results in LB-like inclusions in anatomically connected brain regions, including the substantia nigra pars compacta ( $\mathrm{SNpc}$ ), the locus responsible for motor symptoms in PD. We stained tissue from these mice with antibodies which recognize TH (a marker for dopamine neurons), pS129 $\alpha$-synuclein, and p-MARK. A subset of SNpc neurons ipsilateral to the $\alpha$-synuclein PFF injection site have $\alpha$-synuclein inclusions and associated p-MARK puncta (Fig.
$7 A, B)$ that appear remarkably similar to those seen in culture (Fig. 6A). SNpc neurons contralateral to the $\alpha$-synuclein PFF injection site show no pS129 immunoreactivity and low p-MARK staining, primarily in the nucleus (Fig. 7C).

\section{Active MARK is localized to LBs in human synucleinopathy CNS tissue}

Given our findings in primary neurons and mouse tissue, we next asked whether p-MARK was detected in human brains with $\alpha$-synuclein inclusions. To do this, we performed immunofluorescence staining on sections of midbrain, hippocampus, and cingulate cortex from postmortem human synucleinopathy tissue. In all cases tested, p-MARK was dramatically enriched in LBs as indicated by immunofluorescence colocalization using two p-MARK antibodies generated against the same epitope (Fig. $8 A, B)$ and similar detection of p-MARK in LBs in adjacent sections by immunohistochemistry (Fig. $8 C$ ). We did not see any localization of p-MARK to glial cytoplasmic inclusions in MSA brains, despite the fact that they have extensive $\alpha$-synucleinpositive glial cytoplasmic inclusion pathology, and no cingulate cortex from normal brain had any accumulation of p-MARK or misfolded $\alpha$-synuclein (Fig. 8D). We again used sequentially extracted human brain tissue to determine the solubility of p-MARK. Whereas p-MARK was nearly undetectable in normal brains bio- 
A
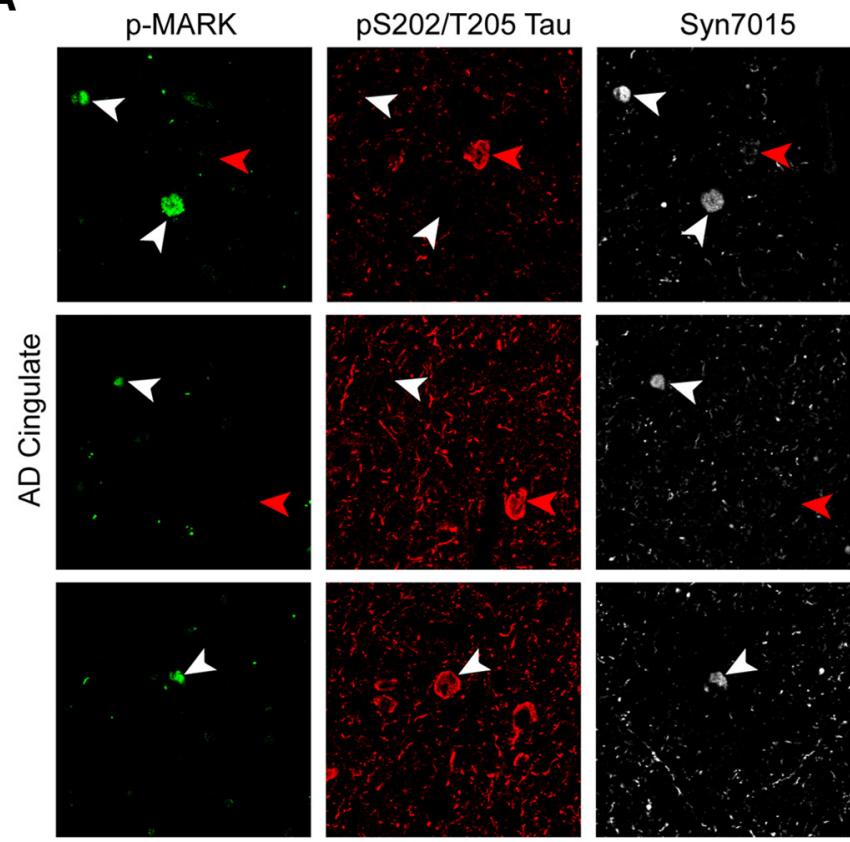

B
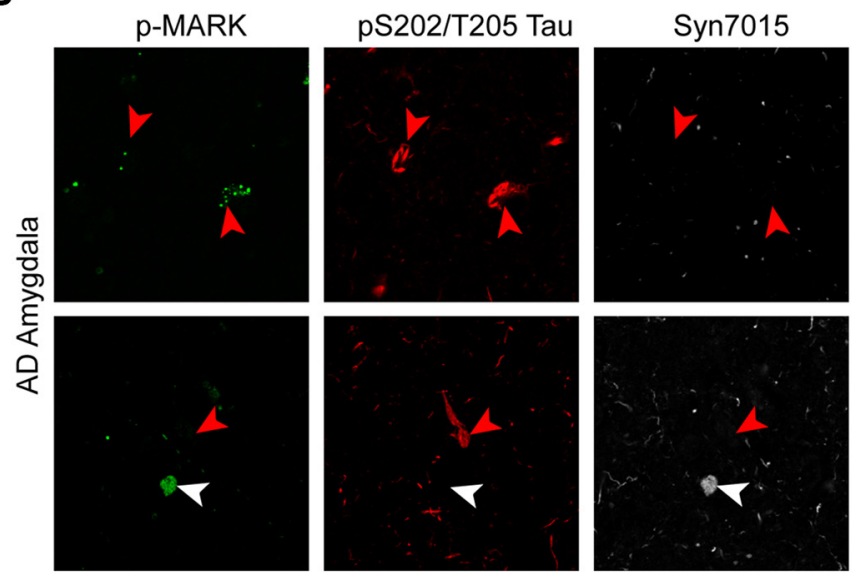

C
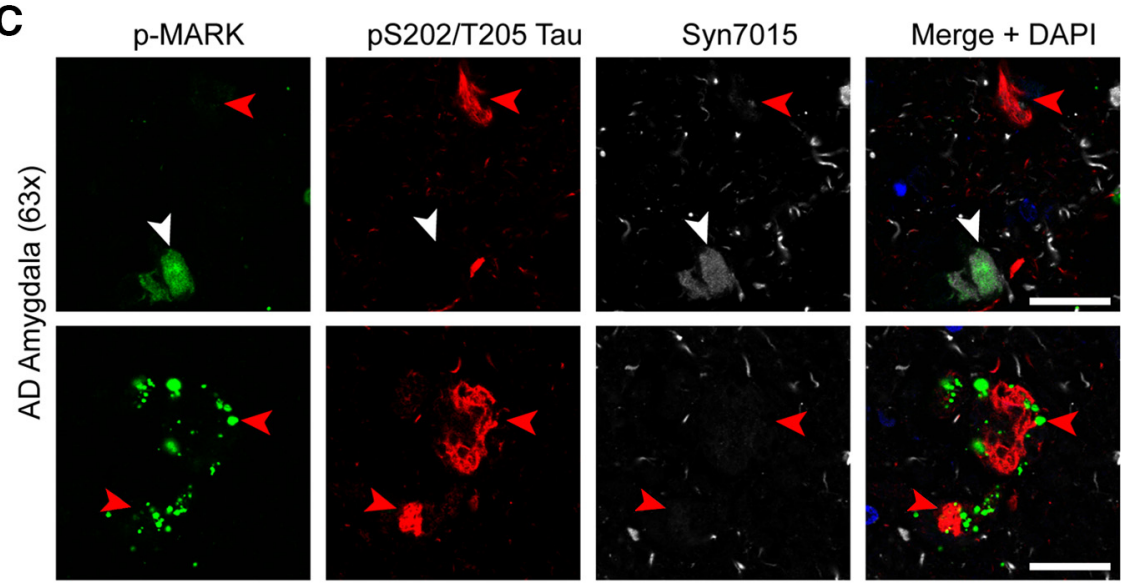

Figure 9. Active MARK is localized primarily to $L B s$ in human $A D$ tissue. $\boldsymbol{A}$, Cingulate gyrus of subjects with $A D$ were immunostained for p-MARK (green), pS202/T205 tau (AT8, red), and misfolded $\alpha$-synuclein (Syn7015, gray). White arrowhead represents $\mathrm{LBs}$. Red arrowhead represents tau tangles. $\boldsymbol{B}, \mathrm{AD}$ amygdala tissue was immunostained as in $\boldsymbol{A}$. $\boldsymbol{C}, \mathrm{LB}$ and tangle inclusions stained as in $\boldsymbol{A}$ and $\boldsymbol{B}$ imaged at a high magnification $(63 \times)$ to demonstrate different structure of associated p-MARK. Scale bars: $\boldsymbol{A}, \boldsymbol{B}, 75$ $\mu \mathrm{m} ; \mathrm{C}, 20 \mu \mathrm{m}$. chemically, PDD and DLB brains had abundant levels of p-MARK in the insoluble fraction (Fig. $8 E, F)$.

Active MARK localization to LBs is conserved across neurodegenerative diseases

The MARK proteins were initially described as regulating the microtubule affinity of microtubule associated proteins, including tau (Drewes et al., 1997), and have been explored in the context of tauopathies, especially $\mathrm{AD}$, but have not been reported to be present in $\alpha$-synuclein pathology. We sought to clarify the relationship of p-MARK to tau and $\alpha$-synuclein inclusions by staining $\mathrm{AD}$ cortex containing both tau tangles and LBs for p-MARK, p-tau (AT8) and misfolded $\alpha$-synuclein (Syn7015). Remarkably, nearly all large p-MARK inclusions in AD cingulate tissue were associated with $\alpha$-synuclein pathology (Fig. 9A). Even p-MARK accumulations in tangle-positive neurons were colocalized with $\alpha$-synuclein pathology (Fig. 9A, third panel). In $\mathrm{AD}$ amygdala, we occasionally found p-MARK puncta in association with neurofibrillary tangles, but similar dots were also found in nearby non-tangle-bearing neurons (Fig. 9B). The dramatically different morphology of p-MARK associated with LBs and tangles can best be appreciated at high magnification in the same tissue where p-MARK can be seen to conform to the shape of the LB but are present as interspersed puncta in tangles (Fig. 9C).

\section{MARK inhibition leads to an}

exacerbation of $\boldsymbol{\alpha}$-synuclein pathology To test the role that MARKs play in $\alpha$-synuclein pathology formation, we used a previously described highly specific chemical inhibitor of MARKs (MKI) (Timm et al., 2011). We applied $\alpha$-synuclein PFFs and MKI simultaneously to 6-d-old primary hippocampal neurons and allowed cells to develop $\alpha$-synuclein pathology for $10 \mathrm{~d}$ before fixation or cell lysis for biochemistry. We observed a remarkable dosedependent effect of MARK inhibition on $\alpha$-synuclein pathology formation (Fig. 10). While MARK inhibition had no effect on overall neuron viability at lower doses, as measured by NeuN count (Fig. 10C), and did not itself induce $\alpha$-synuclein pathology formation, MKI did increase the pS129 $\alpha$-synuclein load in $\alpha$-synuclein PFF-treated neurons by $\sim 2$ fold, at 2-10 $\mu \mathrm{M}$ by ICC (Fig. $10 A, B$ ) and $\sim 1.5$ fold at $10 \mu \mathrm{M}$ by Western blot (Fig. 10C,D), suggesting that MARKs may play a role in LB pathogenesis and the onset and progression of PD and related synucleinopathies. 
A

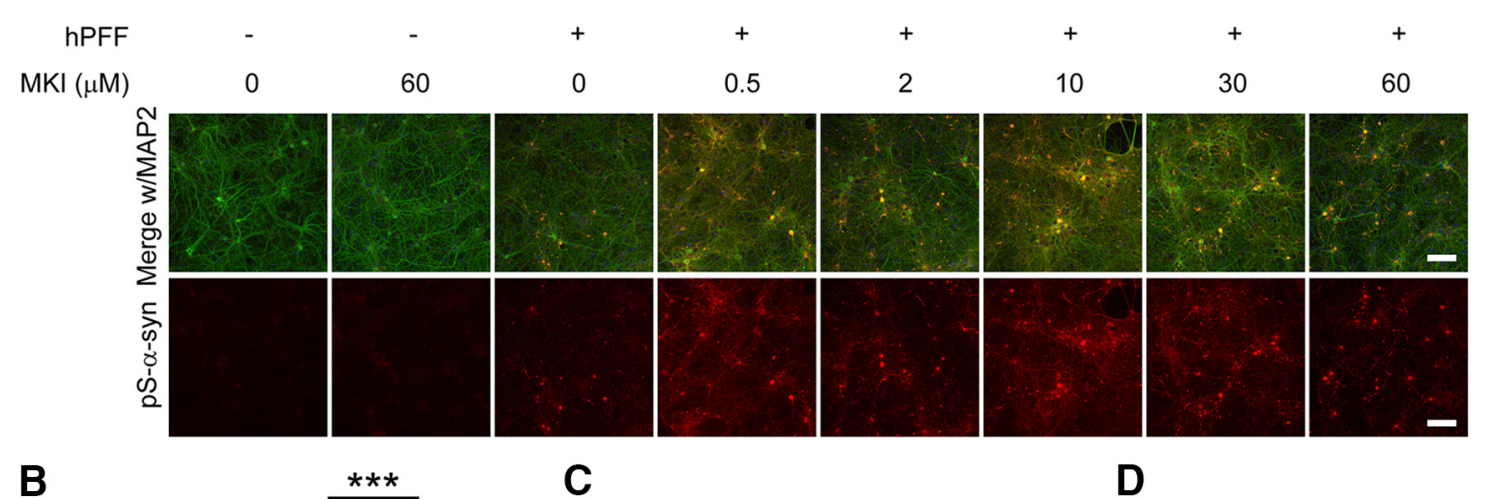

B

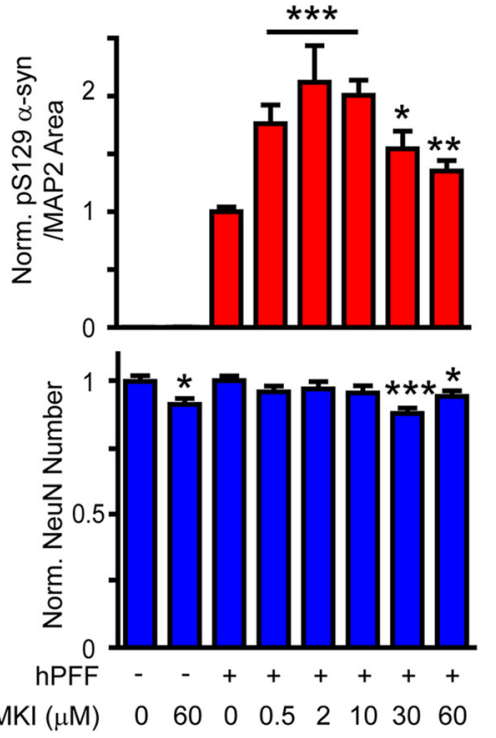

C

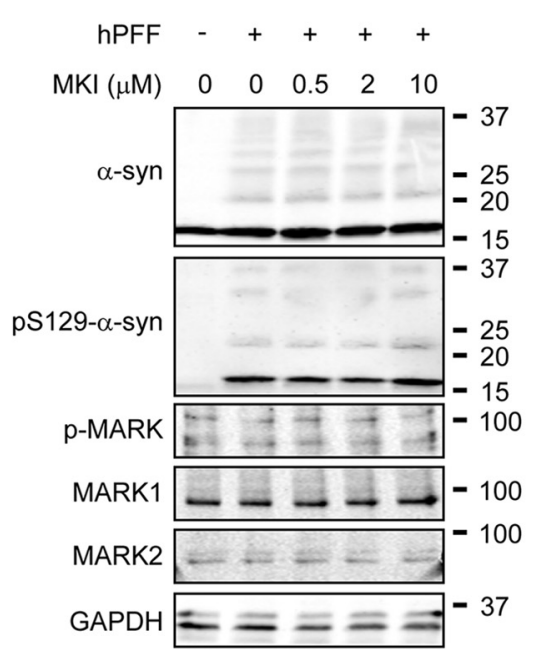

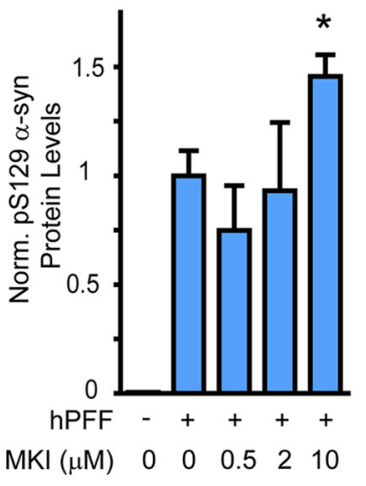

Figure 10. MARK inhibition exacerbates $\alpha$-synuclein pathology. $\boldsymbol{A}$, Primary hippocampal neurons were treated with PBS or $\alpha$-synuclein PFFs and MKI at increasing concentrations or DMSO as a vehicle control. MAP2 stain (green) merged with pS129 $\alpha$-synuclein (red) is shown to indicate the overall health of the cultures. Below, the pS129- $\alpha$-synuclein alone is shown. $\boldsymbol{B}, \mathrm{Quantification}$ of the normalized pS129 $\alpha$-synuclein pathology area/MAP2 area shows a marked dose-dependent change in $\alpha$-synuclein pathology, whereas quantification of NeuN (neuron nuclei marker) shows only small changes at higher concentrations of MKI ( $N=3$ biological replicates, 6 technical replicates each). C, Primary hippocampal neurons treated with PBS or $\alpha$-synuclein PFFs and MKI at increasing concentrations or DMSO as a vehicle control were scraped and extracted with 2\% SDS. Western blot for pS129 $\alpha$-synuclein showed an MKI dose-dependent increase in pathology as quantified in $\boldsymbol{D}\left(N=3\right.$ biological replicates). Scale bars: $\boldsymbol{A}, 100 \mu \mathrm{m}$. Data are mean \pm SEM. ${ }^{* * *} p<0.001$ (two-tailed Mann-Whitney tests for immunocytochemistry). ${ }^{* *} p<0.01$ (two-tailed Mann-Whitney tests for immunocytochemistry). ${ }^{*} p<0.05$ (two-tailed Mann-Whitney tests for immunocytochemistry). ${ }^{*} p<0.05$ (two-tailed $t$ test for Western blot).

\section{Discussion}

Many previous studies have explored the protein content of LBs, leading to the identification of $>90$ proteins in these intraneuronal inclusions (Wakabayashi et al., 2013). We confirm that many proteins copurify with the detergent-insoluble fraction of synucleinopathy brains (Fig. 3), but early pathogenic changes in protein distribution are likely to be obscured at disease end-stage by proteins that are nonspecifically trapped in degenerating neurons harboring LBs. In this study, we sought to investigate protein pathways disrupted in synucleinopathies by using unbiased proteomic analysis of $\alpha$-synuclein inclusions in primary hippocampal neurons before the onset of neurodegeneration. Of the large number of proteins detected by LC-MS/MS and subsequently verified by Western blot, only a small number were sequestered in detergent-insoluble aggregates, consistent with an early stage of aggregate formation.

Among the proteins we identified as increased in the insoluble fraction of PFF-treated neurons are three primary components of LBs ( $\alpha$-synuclein, ubiquitin, p62), two kinases (MARK1, PAK2), two large ubiquitin ligases (HECTD1, HERC1), extracellular matrix protein collagen XII A1, and other proteins (Trp53bp1,
Tbc1D10B, Plc $\beta 1$ ) (Fig. 1; Table 1). As ubiquitination has been extensively implicated in neurodegenerative disease, identification of two E3 ubiquitin ligases HECTD1 and HERC1 is intriguing. HERC1 mutation in mice leads to cerebellar degeneration (Mashimo et al., 2009) and in humans can lead to intellectual disability (Ortega-Recalde et al., 2015; Nguyen et al., 2016). PLC $\beta 1$ has previously been demonstrated to be bound to $\alpha$-synuclein and elevated in neuroblastoma cells overexpressing $\alpha$-synuclein (Guo et al., 2012). Collagen XII A1 expression is not well characterized in brain tissue, but we found increased localization of collagen XII A1 with LB-containing neurons (Fig. 4C). PAK2, Trp53bp1, and TBC1D10B did not show any increased localization to LBs with available antibodies (data not shown).

MARKs were originally identified as kinases that phosphorylate tau in its microtubule binding repeat domain (Drewes et al., 1995, 1997), which decreases binding of tau to microtubules thereby destabilizing them (Matenia and Mandelkow, 2009) or altering microtubule-dependent transport (Mandelkow et al., 2004). Activated MARK puncta have been observed in cells bearing granulovacuolar degeneration bodies (Lund et al., 2014), whereas other studies have demonstrated MARKs in close prox- 
imity to AD tangles (Chin et al., 2000; Gu et al., 2013). However, activated MARK seems to be present primarily in small puncta near granulovacuolar degeneration pathology (Lund et al., 2014), and alterations in MARK solubility have not been demonstrated.

Recently, MARKs have been implicated in PD pathways. MARK2 was shown to activate a cleaved form of phosphatase and tensin homology-induced kinase 1, regulating mitochondrial transport (Matenia et al., 2012). A screen for substrates of the leucine-rich repeat kinase 2 identified MARK1 as a direct substrate of this activity (Krumova et al., 2015). These recent findings suggest that MARKs may play a role in the pathogenesis of PD, and our data are the first demonstration of a direct role for MARKs in sporadic PD.

Specifically, an activated form of MARKs, as identified by a phosphorylated threonine in the activation loop, is localized to cell bodies bearing pS129 $\alpha$-synuclein inclusions in culture neurons (Fig. 6), in vivo in mice (Fig. 7), and in human postmortem synucleinopathy tissue in LBs (Figs. 8, 9). Interestingly, the "less mature" $\alpha$-synuclein inclusions in culture and in mice, which have a nest-like structure, are associated with punctate p-MARK, while mature LBs in human brain have a compact structure and are completely colocalized with p-MARK. Together, the conserved localization through multiple models and species argues for the role of MARKs in $\alpha$-synucleinopathies. Indeed, because inhibition of MARKs increased $\alpha$-synuclein pathology, MARKs may play a protective role in $\alpha$-synuclein pathogenesis. One potential mechanism by which MARKs could facilitate clearance of pathological $\alpha$-synuclein is through its known function in speeding axonal transport (Mandelkow et al., 2004), thereby enhancing autophagic protein degradation in neurons. The possibility that MARKs are directly involved in phosphorylation of $\alpha$-synuclein is dramatically reduced by the failure of overexpressed MARK1 to phosphorylate $\alpha$-synuclein in HEK cells and the increase in pathological pS129 $\alpha$-synuclein phosphorylation upon MARK inhibition. However, we cannot rule out that MARKs are part of a kinase cascade that could result in enhanced $\alpha$-synuclein phosphorylation, and further studies are necessary to clarify the mechanism by which MARKs are involved in $\alpha$-synuclein pathogenesis. Our novel findings implicate MARKs in early LB formation, thereby suggesting that MARKs could be potential therapeutic targets in PD and related synucleinopathies.

\section{References}

Appel-Cresswell S, Vilarino-Guell C, Encarnacion M, Sherman H, Yu I, Shah B, Weir D, Thompson C, Szu-Tu C, Trinh J, Aasly JO, Rajput A, Rajput AH, Jon Stoessl A, Farrer MJ (2013) Alpha-synuclein p.H50Q, a novel pathogenic mutation for Parkinson's disease. Mov Disord 28:811-813. CrossRef Medline

Baba M, Nakajo S, Tu PH, Tomita T, Nakaya K, Lee VM, Trojanowski JQ, Iwatsubo T (1998) Aggregation of alpha-synuclein in Lewy bodies of sporadic Parkinson's disease and dementia with Lewy bodies. J Pathol 152:879-884. Medline

Burns TF, Fei P, Scata KA, Dicker DT, El-Deiry WS (2003) Silencing of the novel p53 target gene Snk/Plk2 leads to mitotic catastrophe in paclitaxel (taxol)-exposed cells. Mol Cell Biol 23:5556-5571. CrossRef Medline

Chartier-Harlin MC, Kachergus J, Roumier C, Mouroux V, Douay X, Lincoln S, Levecque C, Larvor L, Andrieux J, Hulihan M, Waucquier N, Defebvre L, Amouyel P, Farrer M, Destée A (2004) Alpha-synuclein locus duplication as a cause of familial Parkinson's disease. Lancet 364:1167-1169. CrossRef Medline

Chin JY, Knowles RB, Schneider A, Drewes G, Mandelkow EM, Hyman BT (2000) Microtubule-affinity regulating kinase (MARK) is tightly associated with neurofibrillary tangles in Alzheimer brain: a fluorescence resonance energy transfer study. J Neuropathol Exp Neurol 59:966-971. CrossRef Medline

Drewes G, Trinczek B, Illenberger S, Biernat J, Schmitt-Ulms G, Meyer HE,
Mandelkow EM, Mandelkow E (1995) Microtubule-associated protein/ microtubule affinity-regulating kinase (p110mark): a novel protein kinase that regulates tau-microtubule interactions and dynamic instability by phosphorylation at the Alzheimer-specific site serine 262. J Biol Chem 270:7679-7688. CrossRef Medline

Drewes G, Ebneth A, Preuss U, Mandelkow EM, Mandelkow E (1997) MARK, a novel family of protein kinases that phosphorylate microtubuleassociated proteins and trigger microtubule disruption. Cell 89:297-308. CrossRef Medline

Duda JE, Giasson BI, Gur TL, Montine TJ, Robertson D, Biaggioni I, Hurtig HI, Stern MB, Gollomp SM, Grossman M, Lee VM, Trojanowski JQ (2000) Immunohistochemical and biochemical studies demonstrate a distinct profile of alpha-synuclein permutations in multiple system atrophy. J Neuropathol Exp Neurol 59:830-841. CrossRef Medline

Fujiwara H, Hasegawa M, Dohmae N, Kawashima A, Masliah E, Goldberg MS, Shen J, Takio K, Iwatsubo T (2002) alpha-Synuclein is phosphorylated in synucleinopathy lesions. Nat Cell Biol 4:160-164. CrossRef Medline

Galvin JE, Lee VM, Baba M, Mann DM, Dickson DW, Yamaguchi H, Schmidt ML, Iwatsubo T, Trojanowski JQ (1997) Monoclonal antibodies to purified cortical Lewy bodies recognize the mid-size neurofilament subunit. Ann Neurol 42:595-603. CrossRef Medline

Goedert M, Spillantini MG (1998) Lewy body diseases and multiple system atrophy as alpha-synucleinopathies. Mol Psychiatry 3:462-465. CrossRef Medline

Gu GJ, Wu D, Lund H, Sunnemark D, Kvist AJ, Milner R, Eckersley S, Nilsson LN, Agerman K, Landegren U, Kamali-Moghaddam M (2013) Elevated MARK2-dependent phosphorylation of Tau in Alzheimer's disease. J Alzheimers Dis 33:699-713. CrossRef Medline

Guo JL, Covell DJ, Daniels JP, Iba M, Stieber A, Zhang B, Riddle DM, Kwong LK, Xu Y, Trojanowski JQ, Lee VM (2013) Distinct alpha-synuclein strains differentially promote tau inclusions in neurons. Cell 154:103117. CrossRef Medline

Guo Y, Rosati B, Scarlata S (2012) alpha-Synuclein increases the cellular level of phospholipase Cbeta1. Cell Signal 24:1109-1114. CrossRef Medline

Ibáñez P, Bonnet AM, Débarges B, Lohmann E, Tison F, Pollak P, Agid Y, Dürr A, Brice A (2004) Causal relation between alpha-synuclein gene duplication and familial Parkinson's disease. Lancet 364:1169-1171. CrossRef Medline

Irwin DJ, White MT, Toledo JB, Xie SX, Robinson JL, Van Deerlin V, Lee VM, Leverenz JB, Montine TJ, Duda JE, Hurtig HI, Trojanowski JQ (2012) Neuropathologic substrates of Parkinson disease dementia. Ann Neurol 72:587-598. CrossRef Medline

Iwai A, Masliah E, Yoshimoto M, Ge N, Flanagan L, de Silva HA, Kittel A, Saitoh T (1995) The precursor protein of non-A beta component of Alzheimer's disease amyloid is a presynaptic protein of the central nervous system. Neuron 14:467-475. CrossRef Medline

Iwatsubo T, Yamaguchi H, Fujimuro M, Yokosawa H, Ihara Y, Trojanowski JQ, Lee VM (1996) Purification and characterization of Lewy bodies from the brains of patients with diffuse Lewy body disease. J Pathol 148: 1517-1529. Medline

Kiely AP, Asi YT, Kara E, Limousin P, Ling H, Lewis P, Proukakis C, Quinn N, Lees AJ, Hardy J, Revesz T, Houlden H, Holton JL (2013) alphaSynucleinopathy associated with G51D SNCA mutation: a link between Parkinson's disease and multiple system atrophy? Acta Neuropathol 125: 753-769. CrossRef Medline

Krüger R, Kuhn W, Müller T, Woitalla D, Graeber M, Kösel S, Przuntek H, Epplen JT, Schöls L, Riess O (1998) Ala30Pro mutation in the gene encoding alpha-synuclein in Parkinson's disease. Nat Genet 18:106-108. CrossRef Medline

Krumova P, Reyniers L, Meyer M, Lobbestael E, Stauffer D, Gerrits B, Muller L, Hoving S, Kaupmann K, Voshol J, Fabbro D, Bauer A, Rovelli G, Taymans JM, Bouwmeester T, Baekelandt V (2015) Chemical genetic approach identifies microtubule affinity-regulating kinase 1 as a leucinerich repeat kinase 2 substrate. FASEB J 29:2980-2992. CrossRef Medline

Kuusisto E, Parkkinen L, Alafuzoff I (2003) Morphogenesis of Lewy bodies: dissimilar incorporation of alpha-synuclein, ubiquitin, and p62. J Neuropathol Exp Neurol 62:1241-1253. CrossRef Medline

Kuzuhara S, Mori H, Izumiyama N, Yoshimura M, Ihara Y (1988) Lewy bodies are ubiquitinated: a light and electron microscopic immunocytochemical study. Acta Neuropathol 75:345-353. CrossRef Medline 
Lowe J, Blanchard A, Morrell K, Lennox G, Reynolds L, Billett M, Landon M, Mayer RJ (1988) Ubiquitin is a common factor in intermediate filament inclusion bodies of diverse type in man, including those of Parkinson's disease, Pick's disease, and Alzheimer's disease, as well as Rosenthal fibres in cerebellar astrocytomas, cytoplasmic bodies in muscle, and Mallory bodies in alcoholic liver disease. J Pathol 155:9-15. CrossRef Medline

Luk KC, Song C, O’Brien P, Stieber A, Branch JR, Brunden KR, Trojanowski JQ, Lee VM (2009) Exogenous alpha-synuclein fibrils seed the formation of Lewy body-like intracellular inclusions in cultured cells. Proc Natl Acad Sci U S A 106:20051-20056. CrossRef Medline

Luk KC, Kehm V, Carroll J, Zhang B, O’Brien P, Trojanowski JQ, Lee VM (2012) Pathological alpha-synuclein transmission initiates Parkinsonlike neurodegeneration in nontransgenic mice. Science 338:949-953. CrossRef Medline

Lund H, Gustafsson E, Svensson A, Nilsson M, Berg M, Sunnemark D, von Euler G (2014) MARK4 and MARK3 associate with early tau phosphorylation in Alzheimer's disease granulovacuolar degeneration bodies. Acta Neuropathol Commun 2:22. CrossRef Medline

Mandelkow EM, Thies E, Trinczek B, Biernat J, Mandelkow E (2004) MARK/PAR1 kinase is a regulator of microtubule-dependent transport in axons. J Cell Biol 167:99-110. CrossRef Medline

Mashimo T, Hadjebi O, Amair-Pinedo F, Tsurumi T, Langa F, Serikawa T, Sotelo C, Guénet JL, Rosa JL (2009) Progressive Purkinje cell degeneration in tambaleante mutant mice is a consequence of a missense mutation in HERC1 E3 ubiquitin ligase. PLoS Genet 5:e1000784. CrossRef Medline

Matenia D, Mandelkow EM (2009) The tau of MARK: a polarized view of the cytoskeleton. Trends Biochem Sci 34:332-342. CrossRef Medline

Matenia D, Hempp C, Timm T, Eikhof A, Mandelkow EM (2012) Microtubule affinity-regulating kinase 2 (MARK2) turns on phosphatase and tensin homolog (PTEN)-induced kinase 1 (PINK1) at Thr-313, a mutation site in Parkinson disease: effects on mitochondrial transport. J Biol Chem 287:8174-8186. CrossRef Medline

Min SH, Suzuki A, Stalker TJ, Zhao L, Wang Y, McKennan C, Riese MJ, Guzman JF, Zhang S, Lian L, Joshi R, Meng R, Seeholzer SH, Choi JK, Koretzky G, Marks MS, Abrams CS (2014) Loss of PIKfyve in platelets causes a lysosomal disease leading to inflammation and thrombosis in mice. Nat Commun 5:4691. CrossRef Medline

Nguyen LS, Schneider T, Rio M, Moutton S, Siquier-Pernet K, Verny F, Boddaert N, Desguerre I, Munich A, Rosa JL, Cormier-Daire V, Colleaux L (2016) A nonsense variant in HERC1 is associated with intellectual disability, megalencephaly, thick corpus callosum and cerebellar atrophy. Eur J Hum Genet 24:455-458. CrossRef Medline

Ortega-Recalde O, Beltrán OI, Gálvez JM, Palma-Montero A, Restrepo CM, Mateus HE, Laissue P (2015) Biallelic HERC1 mutations in a syndromic form of overgrowth and intellectual disability. Clin Genet 88:e1-e3. CrossRef Medline

Pasanen P, Myllykangas L, Siitonen M, Raunio A, Kaakkola S, Lyytinen J, Tienari PJ, Poyhonen M, Paetau A (2014) Novel alpha-synuclein mutation A53E associated with atypical multiple system atrophy and Parkinson's disease-type pathology. Neurobiol Aging 35:e2181-2185. CrossRef Medline

Polymeropoulos MH, Lavedan C, Leroy E, Ide SE, Dehejia A, Dutra A, Pike B,
Root H, Rubenstein J, Boyer R, Stenroos ES, Chandrasekharappa S, Athanassiadou A, Papapetropoulos T, Johnson WG, Lazzarini AM, Duvoisin RC, Di Iorio G, Golbe LI, Nussbaum RL (1997) Mutation in the alphasynuclein gene identified in families with Parkinson's disease. Science 276:2045-2047. CrossRef Medline

Proukakis C, Dudzik CG, Brier T, MacKay DS, Cooper JM, Millhauser GL, Houlden H, Schapira AH (2013) A novel alpha-synuclein missense mutation in Parkinson disease. Neurology 80:1062-1064. CrossRef Medline

Singleton AB, Farrer M, Johnson J, Singleton A, Hague S, Kachergus J, Hulihan M, Peuralinna T, Dutra A, Nussbaum R, Lincoln S, Crawley A, Hanson M, Maraganore D, Adler C, Cookson MR, Muenter M, Baptista M, Miller D, Blancato J, et al. (2003) alpha-Synuclein locus triplication causes Parkinson's disease. Science 302:841. CrossRef Medline

Spillantini MG, Schmidt ML, Lee VM, Trojanowski JQ, Jakes R, Goedert M (1997) Alpha-synuclein in Lewy bodies. Nature 388:839-840. CrossRef Medline

Spillantini MG, Crowther RA, Jakes R, Cairns NJ, Lantos PL, Goedert M (1998a) Filamentous alpha-synuclein inclusions link multiple system atrophy with Parkinson's disease and dementia with Lewy bodies. Neurosci Lett 251:205-208. CrossRef Medline

Spillantini MG, Crowther RA, Jakes R, Hasegawa M, Goedert M (1998b) alpha-Synuclein in filamentous inclusions of Lewy bodies from Parkinson's disease and dementia with Lewy bodies. Proc Natl Acad Sci U S A 95:6469-6473. CrossRef Medline

Tanik SA, Schultheiss CE, Volpicelli-Daley LA, Brunden KR, Lee VM (2013) Lewy body-like alpha-synuclein aggregates resist degradation and impair macroautophagy. J Biol Chem 288:15194-15210. CrossRef Medline

Timm T, von Kries JP, Li X, Zempel H, Mandelkow E, Mandelkow EM (2011) Microtubule affinity regulating kinase activity in living neurons was examined by a genetically encoded fluorescence resonance energy transfer/fluorescence lifetime imaging-based biosensor: inhibitors with therapeutic potential. J Biol Chem 286:41711-41722. CrossRef Medline

Tu PH, Galvin JE, Baba M, Giasson B, Tomita T, Leight S, Nakajo S, Iwatsubo T, Trojanowski JQ, Lee VM (1998) Glial cytoplasmic inclusions in white matter oligodendrocytes of multiple system atrophy brains contain insoluble alpha-synuclein. Ann Neurol 44:415-422. CrossRef Medline

Volpicelli-Daley LA, Luk KC, Patel TP, Tanik SA, Riddle DM, Stieber A, Meaney DF, Trojanowski JQ, Lee VM (2011) Exogenous alpha-synuclein fibrils induce Lewy body pathology leading to synaptic dysfunction and neuron death. Neuron 72:57-71. CrossRef Medline

Volpicelli-Daley LA, Luk KC, Lee VM (2014) Addition of exogenous alphasynuclein preformed fibrils to primary neuronal cultures to seed recruitment of endogenous alpha-synuclein to Lewy body and Lewy neurite-like aggregates. Nat Protoc 9:2135-2146. CrossRef Medline

Wakabayashi K, Tanji K, Odagiri S, Miki Y, Mori F, Takahashi H (2013) The Lewy body in Parkinson's disease and related neurodegenerative disorders. Mol Neurobiol 47:495-508. CrossRef Medline

Zarranz JJ, Alegre J, Gómez-Esteban JC, Lezcano E, Ros R, Ampuero I, Vidal L, Hoenicka J, Rodriguez O, Atarés B, Llorens V, Gomez Tortosa E, del Ser T, Muñoz DG, de Yebenes JG (2004) The new mutation, E46K, of alphasynuclein causes Parkinson and Lewy body dementia. Ann Neurol 55: 164-173. CrossRef Medline 